\title{
Memory of land surface and subsurface temperature (LST/SUBT) initial anomalies over Tibetan Plateau in different land models
}

Yuan Qiu ( $\sim$ qiuyuan@tea.ac.cn )

Institute of Atmospheric Physics Chinese Academy of Sciences https://orcid.org/0000-0002-4531077X

Jinming Feng

Institute of Atmospheric Physics Chinese Academy of Sciences

Jun Wang

Institute of Atmospheric Physics Chinese Academy of Sciences

Yongkang Xue

University of California Los Angeles

\section{Zhongfeng Xu}

Institute of Atmospheric Physics Chinese Academy of Sciences

\section{Research Article}

Keywords: soil temperature, soil memory, land surface model, Tibetan Plateau, subseasonal to seasonal (S2S) prediction

Posted Date: July 12th, 2021

DOl: https://doi.org/10.21203/rs.3.rs-207060/v1

License: (c) (1) This work is licensed under a Creative Commons Attribution 4.0 International License. Read Full License 


\section{Abstract}

This study applies three widely used land models (SSiB, CLM, and Noah-MP) coupled in a regional climate model to quantitatively assess their skill in preserving the imposed $\pm 5^{\circ} \mathrm{C}$ anomalies on the initial land surface and subsurface temperature (LST/SUBT) and generating the 2-m air temperature (T2m) anomalies over Tibetan Plateau (TP) during May-August. The memory of the LST/SUBT initial anomalies (surface/soil memory) is defined as the first time when time series of the differences in daily LST/SUBT cross the zero line during the simulation, with the unit of days. The memory of the T2m anomalies (T2m memory) is defined in the same way. The ensemble results indicate that the simulated soil memory generally increases with soil depth, which is consistent with the results based on the observations with statistic methods. And the soil memory is found to change rapidly with depth above $\sim 0.6-0.7 \mathrm{~m}$ and vary gradually below it. The land models have fairly long soil memories, with the regional mean $1.0-\mathrm{m}$ soil memory generally longer than 60 days. However, they have short T2m memory, with the regional means generally below 20 days. This may bring a big challenge to use the LST/SUBT approach on sub-seasonal to seasonal (S2S) prediction. Comparison between the three land models shows that CLM and Noah-MP have longer soil memory at the deeper layers $(>\sim 0.05 \mathrm{~m})$ while SSiB has longer T2m/surface memories and near-surface ( $\leq \sim 0.05 \mathrm{~m}$ ) soil memory. As a result, it is difficult to say which land model is optimal for the application of the LST/SUBT approach on the S2S prediction. The T2m/surface/soil memories are various over TP, distinct among the land models, and different between the $+5^{\circ} \mathrm{C}$ and $-5^{\circ} \mathrm{C}$ experiment, which can be explained by both changes in the surface heat fluxes and variances in the hydrological processes over the plateau.

\section{Introduction}

Subseasonal to seasonal (S2S) prediction of extreme hydroclimate events such as droughts and floods is crucial due to their enormous social, economic, and environmental impacts (Merryfield et al., 2020). Extensive studies have shown that sea surface temperature (SST) variability have predictive value for land precipitation (Barlow et al., 2001; Jia and Yang, 2013; Seager et al., 2014; Ting and Wang, 1997; Trenberth et al., 1988). However, SSTs alone only partially explain the phenomena of predictability (Mei and Wang, 2011; Mo et al., 2009; Pu et al., 2016; Rajagopalan et al., 2000; Scaife et al., 2009; Schubert et al., 2009; Schubert et al., 2004; Xue et al., 2016a; Xue et al., 2018; Xue et al., 2016b). Recent studies based on climate observations and model simulations have suggested that the remote (non-local) effects of large-scale land surface/subsurface temperature (LST/SUBT) anomalies in geographical areas upstream on their downstream regions is probably as large as the more familiar effects of SST (Diallo et al., 2019; Shukla et al., 2019; Xue et al., 2018; Xue et al., 2016b). For instance, the spring warm 2-m air temperature (T2m)/LST/SUBT anomalies in western U.S. are demonstrated to have a causal relationship with the extraordinary 2015 flood in Southern Great Plains and adjacent regions, and combination of LST/SUBT anomalies and SST can fully explain the phenomena (Xue et al., 2018; Xue et al., 2016b).

To pursue a new gateway in improving the S2S prediction with the application of the LST/SUBT 
Study (GASS) have supported the establishment of a new Initiative called "Impact of initialized land temperature and snowpack on sub-seasonal to seasonal prediction" (LS4P, Xue et al., 2019). This project intends to test the impact of model initialization of LST/SUBT on the S2S prediction with multiple Earth System Models (ESMs) and regional climate models (RCMs). The first phase of LS4P investigates the Tibetan Plateau effect because the high elevation and large-scale, persistent LST anomalies there provide an ideal geographic location for the test. Furthermore, numerous studies have reported that the Tibetan Plateau's thermal and dynamic forcing drive the Asian monsoon through a huge, elevated heat source in the middle troposphere (Wang et al., 2008; Wu et al., 2007; Yanai et al., 1992; Yao et al., 2019; Ye, 1981).

May and June 2003 are selected for the main tests in Phase I (Xue et al., 2021). The summer of 2003 was characterized by a severe drought/flood over the southern/northern part of the Yangtze River Basin in eastern China and an abnormally cold spring in Tibetan Plateau. To test the effect of May 2003 T2m/LST/SUBT anomalies in Tibetan Plateau on June 2003 precipitation, the climate models have to reproduce the observed May T2m anomaly. The previous practice suggested that the only way to produce the observed T2m anomalies in the model integration is imposing both LST/SUBT initial anomalies in Tibetan Plateau based on the observed T2m anomalies and model bias (Xue et al., 2021).

Ideally, the LST/SUBT initial anomalies in the Tibetan Plateau could influence the lower and middle atmospheric layers and further affect the circulation pattern downstream through the wave train that is generated through the surface heating perturbation, which eventually plays an importance role in the occurrence of droughts and floods in late spring/summer over the eastern part of Asia. However, the LS4P ESMs and RCMs with their land models are generally unable to hold the imposed LST/SUBT anomalies well during the model integration and thus have difficulty in generating the observed T2m anomaly over the Tibetan Plateau (Xue et al., 2021). Our premise is that the current models' deficiencies in maintaining the LST/SUBT initial anomalies are mainly rooted in their land parameterizations.

Previous studies have shown that the land models generally miss some key land surface processes in the Tibetan Plateau (Liu et al., 2020; Yang et al., 2009). For instance, the abundant organic matter beneath the alpine meadows in the central and eastern Tibetan Plateau is generally not taken into account in the land models. Less soil organic matter increases soil thermal conductivity and decreases soil heat capacity, which could cause the rapid loss of soil thermal anomalies in the models. In addition, high soil moisture and shallow soil layer depth in the land models also hamper the preservation of soil temperature anomaly in the Tibetan Plateau (Liu et al., 2020; Su et al., 2011).

The low skill of the LS4P models in keeping the LST/SUBT initial anomalies and reproducing the observed T2m anomaly underscores the need to investigate the memory of LST/SUBT initial anomalies (referred as the surface/soil memory) and the responses of surface air temperature to the anomalies over the Tibetan Plateau in different land models. It is also imperative to understand the inherent mechanisms.

Thus, this study applies three widely used land models (SSiB, CLM, and Noah-MP, Table 1), which are Loading [MathJax]/jax/output/CommonHTML/fonts/TeX/fontdata.js and Forecasting (WRF, Skamarock et al., 2008) 
and intends to address three questions:

- How long do the LST/SUBT initial anomalies last in these land models?

- How does T2m response to the LST/SUBT initial anomalies in each model?

- What are the major physical processes to regulate the surface/soil memories and the responses of T2m to the LST/SUBT initial anomalies?

Here we focus on quantitatively assessing the ability of different land models in preserving the LST/SUBT initial anomalies and generating T2m anomaly, which could help better understand the LST/SUBT approach for the S2S prediction and provide practical notes for the relevant numerical simulations. The rest of this article is organized as follows. Section 2 describes the data and methods. The results are presented in Sect. 3, followed by the mechanism explaining in Sect. 4. Major conclusions and some discussions are in Sect. 5.

\section{Data And Methods}

\subsection{Experimental design}

In this study, the WRF model is used in a single (non-nested) domain of $25 \mathrm{~km} \times 25 \mathrm{~km}$ resolution covering East Asia (the blue area in Fig. 1). The model has 35 levels in the vertical direction with its top fixed at 50 $\mathrm{hPa}$. Its initial and boundary conditions are from the ERA-Interim reanalysis data (Dee et al., 2011). In it, three land surface models (LSMs) are separately chosen to simulate the exchange of surface water and energy fluxes at the soil-atmosphere interface. They are the Simplified Simple Biosphere (referred as SSiB) Model, Community Land Model Version 4 (referred as CLM) and Noah-MP(multi-physics). SSiB and Noah-MP solve Richards equation to derive soil moisture for each soil layer, while CLM's soil moisture is estimated by adopting an improved one-dimensional Richards equation (Zeng and Decker, 2009). The force-restore method is used to derive the soil temperature in SSiB, while CLM and Noah-MP calculate the evolution of the soil temperature by solving the thermal diffusion equation. Other main physical parameterizations in the WRF model are the New Simplified Arakawa-Schubert (SAS) cumulus scheme (Han and Pan, 2011), the Yonsei University (YSU) planetary boundary layer scheme (Hong et al., 2006), the New Thompson microphysics scheme, and the RRTMG shortwave and longwave schemes (lacono et al., 2008).

To assess the skill of the LSMs in maintaining the LST/SUBT initial anomalies, three experiments are designed for each LSM coupled in the WRF model. They are the control, $+5^{\circ} \mathrm{C}$ and $-5^{\circ} \mathrm{C}$ experiment. Compared with the control experiment, the only difference in the $\pm 5^{\circ} \mathrm{C}$ experiment is that the air temperature at the bottom layer, land surface temperature and subsurface temperature of all layers over the Tibetan Plateau (the yellow area in Fig. 1) at the initial time are modified by adding $\pm 5^{\circ} \mathrm{C}$ to their original values. The initial soil moisture and snow conditions are from the driving data, the ERA-Interim reanalysis, and are consistent between all the experiments. May-August of six years $(1987,1991,1996$, 1008 2nก2 and 2nn7) aro calontad for tho cimulation Among them, 1987 and 2003 (1998 and 2007) Loading [MathJax]/jax/output/CommonHTML/fonts/TeX/fontdata.js 
have abnormally cold (warm) spring in the Tibetan Plateau during 1981-2010 (Fig. 2). In addition, 1991 and 1996 are normal years based on a threshold of half standard deviation of the T2m anomaly variability $\left(0.37^{\circ} \mathrm{C}\right)$. Thus, there are totally $54(6 \times 3 \times 3)$ runs in this study. Each run is from May 1 to August 31 , as long as 123 days, which covers the simulation duration (May-June) of the LS4P models and meanwhile is long enough to assess the surface/soil memories.

The reason why we use $\pm 5^{\circ} \mathrm{C}$ instead of the anomalies calculated based on the observed $T 2 \mathrm{~m}$ anomalies and model bias (see Eq. 1a-b in Xue et al., 2021) is that imposing a uniform anomaly makes it possible to assess the surface/soil memories over areas of different weather/climate conditions and land surface features (such as vegetation, soil moisture, and snow) in Tibetan Plateau. Note that the objective of this study is to compare the T2m/surface/soil memories between different LSMs, not to reproduce the observed T2m anomalies as in Xue et al. (2021). The $\pm N^{\circ} \mathrm{C}(\mathrm{N}=1,3)$ experiments for a single year (2003) are also conducted and it is found that the LST/SUBT perturbations in these experiments are so weak that the produced surface/soil memories are too short to do the comparison between the LSMs. Thus, $\mathrm{N}$ is set as 5 in this study. The ensemble means of the model results are presented hereafter.

\subsection{Definition of the memory of the LST/SUBT initial anomalies}

The memories of the LST/SUBT initial anomalies (surface/soil memories) are defined as how long the abnormal signals can last in the model integration, that is to say, the first time when the abnormal signals cross the zero line, with the unit of days. The abnormal signals are time series of the differences in the daily LST/SUBT between the control and $\pm 5^{\circ} \mathrm{C}$ experiment. And the three-point smoothing method is applied to erase the high-frequency oscillations in the time series. For instance, Fig. 3 illustrates the smoothed time series of the differences in daily soil temperature at the layer of $0.25 \mathrm{~m}$ between the control and $+5^{\circ} \mathrm{C}$ experiment with the land model of Noah-MP on a randomly selected model grid $\left(35.3^{\circ} \mathrm{N}, 88.4^{\circ} \mathrm{E}\right)$ during 2003 . The abnormal signal is above $3^{\circ} \mathrm{C}$ in the beginning of the simulation, gradually decreases to zero after $\sim 22$ days since the initial time and then oscillates around the zero line. As a result, the soil memory at $0.25 \mathrm{~m}$ is $\sim 22$ days on this model grid. The memory of T2m anomaly (referred to as T2m memory) is defined in the same way, as an index to assess the responses of surface air temperature to the LST/SUBT initial anomalies.

Because of the various weather/climate conditions and land surface feathers over the Tibetan Plateau, the $T 2 \mathrm{~m} /$ surface/soil memories are calculated on each model grid, instead of on the whole region. Since the land models have different soil layers (Table 1), the soil memories are also linearly interpolated to three specified layers $(0.05,0.50$, and $1.0 \mathrm{~m})$ based on their adjacent two original layers so as to do the comparison between the land models.

\subsection{Validation data}

The T2m and precipitation data from the China Meteorological Forcing Dataset (CMFD, He et al., 2020) with a resolution of $0.1^{\circ}$ are used as "observations" to evaluate the model performance over the Tibetan Plateau. This dataset is the first high spatial-temporal resolution gridded near-surface meteorological datacet develoned cnerificallv for ctudiec of land curfare processes in China and made by merging Loading [MathJax]/jax/output/CommonHTML/fonts/TeX/fontdata.js 
various data sources (such as satellite products, reanalysis datasets, and in-situ station data), which is demonstrated to be of superior quality. Before the evaluation, the $\mathrm{T} 2 \mathrm{~m}$ and precipitation gridded data are bilinearly interpolated to the model grides.

\section{Results}

\subsection{Model evaluation}

Comparison with the validation data (CMFD) shows that all the simulations in the control experiments with different land models can well capture the spatial pattern of the observed T2m over the Tibetan Plateau (Fig. 4a-d), with the spatial correlation coefficients in a range of 0.85-0.88 (Table 2). However, large positive biases of T2m are found over the plateau, especially in the simulation with SSiB whose mean bias over the plateau is $2.87^{\circ} \mathrm{C}$. The biases are reduced in the simulations with CLM and Noah-MP, whose mean biases are $1.58^{\circ} \mathrm{C}$ and $1.16^{\circ} \mathrm{C}$, respectively. According to Wu et al. (2021), the longwave radiation term associated with the overestimated water vapor content is likely to contribute to the warm bias over Tibetan Plateau in our simulations. Note that the model-simulated T2m is not adjusted to the elevation height of the validation data before calculating the model bias.

All the simulations also overestimate the precipitation over the Tibetan Plateau, especially in the southern part (Fig. 4e-h), which results in large deviations. For instance, the mean bias in the simulation with Noah$\mathrm{MP}$ is as large as $3.11 \mathrm{~mm} /$ day. However, the precipitation gradient increasing from northwest to southeast over the Tibetan Plateau in the validation data is fairly well simulated, with the spatial correlation coefficients all above 0.60 (Table 2).

To sum up, all the simulations with different land models can well simulate the weather processes over the Tibetan Plateau despite some systematic biases, which provides a good base to the further analyses of the $T 2 \mathrm{~m} /$ surface/soil memories.

\section{$3.2 \mathrm{~T} 2 \mathrm{~m} /$ surface/soil memories}

\subsubsection{The $+5^{\circ} \mathrm{C}$ experiments}

Figure 5 shows boxplots of T2m/surface/soil memories on each model grid over the Tibetan Plateau in the $+5^{\circ} \mathrm{C}$ experiments. Based on the means, medians, and interquartile ranges of the boxplots, it is easy to find that the simulated soil memory generally increases with soil depth, which is consistent with the results based on the observational data with statistics methods (Hu and Feng, 2004; Yang and Zhang, 2016). Figure 6 a reveals that the regional mean soil memory changes rapidly with depth above $\sim 0.6$ $0.7 \mathrm{~m}$ and varies gradually below it. The regional mean soil memories at the layer of $0.62 \mathrm{~m}$ and above in CLM, the layer of $0.7 \mathrm{~m}$ and above in Noah-MP, and the full layers in SSiB (considering it has only three soil layers) are separately linearly fitted with soil depth. The variability of SSiB, CLM, and Noah-MP among their specified layers is 40,105 , and 129 days/m, respectively. 
The data distribution in the boxplots (Fig. 5) shows that the soil memory of SSiB is more aggregated at each layer, meaning that its soil memory is more uniform over the Tibetan Plateau. However, the data of CLM and Noah-MP is more discrete, meaning that their soil memory is more heterogeneous over the plateau. These results are consistent with what the spatial distribution of soil memory indicates (Fig. 7 and S1). For instance, the $0.05 \mathrm{~m}$ soil memory of CLM has a high-value area (> 110 days) in the northern part of the Tibetan Plateau and a large area of low value ( $\leq 10$ days) in the southeastern part (Fig. $7 \mathrm{~h}$ ). And the $0.5 \mathrm{~m}$ soil memory of Noah-MP presents an increasing pattern from northwest to southeast in the plateau (Fig. 7l).

In terms of the magnitude of soil memory, the values of SSiB at the deeper layers $(>\sim 0.05 \mathrm{~m})$ are generally much smaller than those of CLM and Noah-MP over the Tibetan Plateau (Fig. 7 and S1). For instance, the regional mean soil memory at $0.5 \mathrm{~m}$ in SSiB is 39.1 days, while those of CLM and Noah-MP are respectively 101.6 and 85.2 days, which are more than twice of the value of SSiB (Table 3). Although the deeper-layer soil memory of SSiB is much smaller than CLM and Noah-MP, its T2m/surface memories are generally larger than them (Fig. 7a-f). In SSiB, the T2m/surface memories are greater than 10 days in almost the entire region, and even more than 30 days in some areas, with the regional means as large as $\sim 20$ days. However, the T2m/surface memories of Noah-MP and surface memory of CLM are less than 10 days in most parts of the plateau.

Since the T2m memory is different among the land models, differences in May T2m between the control and $+5{ }^{\circ} \mathrm{C}$ experiment are also distinct between them. Figure 8 (the left column) shows the values of SSiB and CLM are positive in almost the entire plateau, while the negative-value areas in Noah-MP accounts for $\sim 60 \%$ of the whole region. Differences in May T2m over most of Tibetan Plateau passed the significance test with the paired sample T-test at the $95 \%$ confidence level (see the slashed areas in Fig. 8).

\subsubsection{The $-5^{\circ} \mathrm{C}$ experiments}

Compared with the results in the $+5^{\circ} \mathrm{C}$ experiments, there are some major differences in the $-5^{\circ} \mathrm{C}$ experiments. The T2m/surface memories and near-surface soil memory ( $\leq \sim 0.05 \mathrm{~m}$ ) of the three land models all increase slightly or remain (comparison of Figs. 7 and 10, Table 3). In terms of the deeper-layer $(>\sim 0.05 \mathrm{~m})$ soil memories, the values of SSiB increase, while those of CLM and Noah-MP largely decrease. For instance, the regional mean $0.5-\mathrm{m}$ soil memory of Noah-MP drops from 85.2 to 48.9 days, with a decrease of $42.6 \%$ (Table 3 ). As a result, the change rate of soil memory with depth among the aforementioned specified layers in SSiB slightly increases from 40 to 47 days $/ \mathrm{m}$, while those of CLM and Noah-MP decrease dramatically. For instance, the change rate of CLM is reduced from 105 to 64 days $/ \mathrm{m}$, and that of Noah-MP drops from 129 to 52 days $/ \mathrm{m}$. Compared with the control experiment, the imposed $-5^{\circ} \mathrm{C}$ initial anomalies reduce the May T2m over almost the entire region in SSiB and CLM (Fig. 8d-e). However, the May T2m of Noah-MP increases in more than half of the plateau (Fig. 8f).

\section{Mechanisms}


The T2m anomaly over Tibetan Plateau plays a significant role in S2S prediction (Xue et al., 2021). The three land models in this study have quite different T2m memory as well as surface/soil memories (e.g., Figs. 7 and 8). The possible causes for these differences are discussed in this section.

It's found that both changes in the surface heat fluxes (sensitive/latent heat fluxes, referred as SH/LH) and variations in the hydrological processes over the Tibetan Plateau can well explain why the $\mathrm{T} 2 \mathrm{~m} /$ surface/soil memories are various over the Tibetan Plateau, distinct among the three land models, and different between the $+5^{\circ} \mathrm{C}$ and $-5^{\circ} \mathrm{C}$ experiment as detected in Sect. 3 .

Figure 11a shows that adding $+5^{\circ} \mathrm{C}$ on the initial LST/SUBT causes a slight increase in SH and LH during the first $\sim 20$ days of the simulation with SSiB, which favors the preservation of the imposed positive T2m anomaly. However, LH in CLM and Noah-MP is triggered to largely increase along with SH decreasing during the simulation, which means LH in these models are very sensitive to the surface temperature and is not favorable for keeping the positive T2m anomaly. Time series of the differences in daily T2m and LST in CLM and Noah-MP (Fig. S3a) shows that increased LH causes LST decrease more rapid than $\mathrm{T} 2 \mathrm{~m}$ and thus time series of the differences in daily temperature gradience between LST and T2m (LST - T2m) turn negative in the very beginning of the simulation (Fig. S3b). This explains why SH decreases in CLM and Noah-MP after adding $+5^{\circ} \mathrm{C}$ on the initial LST/SUBT.

The enhanced LH in CLM and Noah-MP is accompanied with stronger surface evaporation, which strengthens the convection in the atmosphere. For instance, the May equivalent potential temperature (EPT) and convective available potential energy (CAPE, equation S1) averaged over the Tibetan Plateau consistently increase on the lower eta levels in the $+5^{\circ} \mathrm{C}$ experiment (solid lines in Fig. $11 \mathrm{c}-\mathrm{d}$ ). As a result, more precipitation falls on the ground (Fig. 12h-i), which leads to higher soil moisture in the near-surface layers, especially in the simulation with CLM (Fig. 12k-I). And wetter soil in turn exaggerates surface evaporation, which produces a feedback that continuously erases the soil thermal anomalies at the nearsurface layers, as discussed in Xue et al. (2021), and conversely brings benefit in keeping the LST/SUBT anomalies at the deeper layers.

The opposite situations are found in the $-5^{\circ} \mathrm{C}$ experiment. The $-5^{\circ} \mathrm{C}$ initial anomalies causes a slight decrease in $\mathrm{SH}$ and $\mathrm{LH}$ during the first $\sim 40$ days of the simulation with $\mathrm{SSiB}$, which favors in maintaining the imposed negative T2m anomaly. However, LH in CLM and Noah-MP is triggered to largely decrease along with $\mathrm{SH}$ increasing during the simulation (Fig. 11b). The increased $\mathrm{SH}$ is not favorable for keeping the negative $\mathrm{T} 2 \mathrm{~m}$ anomaly.

Meanwhile, the reduced LH in CLM and Noah-MP is accompanied with weaker surface evaporation, which weakens the convection in the atmosphere. For instance, the May EPT and CAPE averaged over the Tibetan Plateau consistently decrease on the lower eta levels in the $-5^{\circ} \mathrm{C}$ experiment (dotted lines in Fig. $11 \mathrm{c}-\mathrm{d}$ ). As a result, less precipitation falls on the ground (Fig. 13h-i), which leads to lower soil moisture at 
hydrological process is good for maintaining the soil thermal anomalies at the near-surface layers and hastens the demise of the soil thermal anomalies at the deeper layers. The feedbacks caused by the imposed LST/SUBT initial anomalies between the soil heat fluxes, surface evaporation, convection in the atmosphere, precipitation, and soil moisture at the near-surface layers in CLM and Noah-MP are concluded in Fig. 14.

Comparison of changes in the surface heat fluxes and the hydrological processes between the land models (the $+5^{\circ} \mathrm{C}$ and $-5^{\circ} \mathrm{C}$ experiment) can well explain why the $\mathrm{T} 2 \mathrm{~m} /$ surface/soil memories are distinct among the land models (between the $+5^{\circ} \mathrm{C}$ and $-5^{\circ} \mathrm{C}$ experiment). Changes in the surfaces heat fluxes, precipitation, and soil moisture are various over the Tibetan Plateau, which results in the heterogeneity of the memories on the spatial distribution. For instance, the areas with increased (decreased) soil moisture at $0.05 \mathrm{~m}$ (Fig. 12k) have shorter (longer) soil memory (Fig. $7 \mathrm{~h}$ ) in the $+5^{\circ} \mathrm{C}$ experiment with CLM.

We calculated percentage of differences in May convective precipitation between the control and $\pm 5^{\circ} \mathrm{C}$ experiment to differences in May total precipitation (Fig. S4) and found that the value is generally above $90 \%$ in the middle and southeastern part of the plateau. This indicates that the aforementioned feedback plays a major role in regulating the $\mathrm{T} 2 \mathrm{~m} /$ surface/soil memories in these areas.

\section{Discussion And Conclusion}

This study applies three widely used land models (SSiB, CLM, and Noah-MP) coupled in the regional climate model WRF to quantitatively assess their skill in preserving the imposed $\pm 5^{\circ} \mathrm{C}$ anomalies on the initial LST/SUBT and generating the T2m anomaly over the Tibetan Plateau during May-August of six years $(1987,1991,1996,1998,2003$, and 2007). The ensemble results in the three land models commonly indicate that the simulated soil memory generally increases with soil depth. And soil memory changes rapidly with depth above $\sim 0.6-0.7 \mathrm{~m}$ and varies gradually below it. However, their change rates are different. For instance, in the $+5^{\circ} \mathrm{C}$ experiment, the variability of SSiB, CLM, and Noah-MP among their specified upper layers is 40,105 , and 129 days/m, respectively.

Moreover, the ensemble results show that the $\mathrm{T} 2 \mathrm{~m} /$ surface/soil memories are distinct between the land models. The soil memory of SSiB is highly uniform over the plateau, while that of CLM and Noah is more heterogeneous. In terms of the magnitude of the memories, the soil memory of SSiB at the deeper layers ( $>\sim 0.05 \mathrm{~m}$ ) are generally smaller than that of CLM and Noah-MP, while the T2m/surface memories and near-surface ( $\leq \sim 0.05 \mathrm{~m}$ ) memory of SSiB are generally larger than them. Differences in May T2m between the control and $\pm 5^{\circ} \mathrm{C}$ experiment are also different between them. For instance, the imposed $5^{\circ} \mathrm{C}$ initial anomalies reduce the May T2m over almost the entire plateau in SSiB and CLM, whereas the May T2m of Noah-MP increases in more than half of the region.

Compared with the $+5^{\circ} \mathrm{C}$ experiment, the $\mathrm{T} 2 \mathrm{~m} /$ surface memories and near-surface soil memory in the $5^{\circ} \mathrm{C}$ experiment with each land model all increase slightly or remain. In terms of the deeper soil memory, Loading [MathJax]/jax/output/CommonHTML/fonts/TeX/fontdata.js hh-MP decreases, especially in the deep soil. As 
a result, the change rate of soil memory with depth among the aforementioned specified layers in SSiB slightly increases from 40 to 47 days/m, while those of CLM and Noah-MP decrease dramatically.

The heterogeneity of the memories over the Tibetan Plateau, their distinctions among the land models, and their differences between the $+5^{\circ} \mathrm{C}$ and $-5^{\circ} \mathrm{C}$ experiment can be welled explained by both changes in the surface heat fluxes and variances in the hydrological processes over the plateau. The feedback caused by the imposed LST/SUBT initial anomalies between the soil heat fluxes, surface evaporation, convection in the atmosphere, precipitation, and soil moisture at the near-surface layers plays a major role in regulating the $\mathrm{T} 2 \mathrm{~m} /$ surface/soil memories, especially in the middle and southeastern part of the plateau. In addition, changes in snow conditions (such as snow melting) and subsequent monsoon circulation alternation can influence the air-land interaction over the Tibetan Plateau and then regulate the $T 2 \mathrm{~m} /$ surface/soil memories. Detailed analyses of changes in these physical processes are out of the scope in the current paper and will be investigated in the next stage.

In this study, the three land models have fairly long soil memories. For instance, the regional mean 1.0-m soil memories in these models are generally longer than 60 days. However, the T2m memory in them is much shorter than soil memory. For instance, the regional mean T2m memories in these models are generally below 20 days. This means that the soil thermal anomalies cannot continuously affect the surface air temperature by the air-land interaction. CLM and Noah-MP have longer soil memory at the deeper layers ( $>\sim 0.05 \mathrm{~m}$ ) while SSiB has longer T2m/surface memories and near-surface memory ( $\leq$ $\sim 0.05 \mathrm{~m}$ ). As a result, it is difficult to say which land model is optimal for the application of the LST/SUBT approach on the S2S prediction.

As a preliminary study in investigating the skill of land models in preserving the soil thermal anomalies, this work is to compare the memory of the LST/SUBT initial anomalies in different land models with their default soil parameters (such as soil textures and soil organic matters), which can give practical notes to the relevant numeric simulations, like those in the LS4P project. Considering the potential effect of different soil parameters in the land models to the $\mathrm{T} 2 \mathrm{~m} /$ surface/soil memories, comparison between the land models with same soil parameters will give a fairer assessment.

\section{Declarations}

\section{Acknowledgement}

The China Meteorological Forcing Dataset (CMFD) used in this study is developed by Data Assimilation and Modeling Center for Tibetan Multi-spheres, Institute of Tibetan Plateau Research, Chinese Academy of Sciences. Thanks for their efforts and honor their spirit of sharing. This study was supported by the National Key R\&D Program of China (2016YFA0600403), the General Project of the National Natural Science Foundation of China (Grant 41875134) and the Strategic Priority Research Program of Chinese Academy of Sciences (Grant No. XDA20020201). 
Funding: This study was supported by the National Key R\&D Program of China (2016YFA0600403), the General Project of the National Natural Science Foundation of China (Grant 41875134) and the Strategic Priority Research Program of Chinese Academy of Sciences (Grant No. XDA20020201).

Conflicts of interest/Competing interests: No conflicts of interest/competing interests.

Availability of data and material: If necessary, the data and materials used in this study will be uploaded to a data center, like National Tibetan Plateau/Third Pole Environment Data Center (http://data.tpdc.ac.cn/).

Code availability: If necessary, the codes of analyzing and plotting in this study will be upload to github.

Authors' contributions: All the authors except Zhongfeng Xu made substantial contributions to the conception or design of the work. Yuan Qiu did analyses and drafted the work and others revised it. Zhongfeng Xu contributed to the mechanism explaining in section 4.

\section{References}

Barlow, M., Nigam, S., and Berbery, E. H., 2001, ENSO, Pacific decadal variability, and US summertime precipitation, drought, and stream flow: Journal of Climate, v. 14, no. 9, p. 2105-2128.

Dee, D. P., Uppala, S. M., Simmons, A., Berrisford, P., Poli, P., Kobayashi, S., Andrae, U., Balmaseda, M., Balsamo, G., and Bauer, d. P., 2011, The ERA-Interim reanalysis: Configuration and performance of the data assimilation system: Quarterly Journal of the royal meteorological society, v. 137, no. 656, p. 553597.

Diallo, I., Xue, Y., Li, Q., De Sales, F., and Li, W., 2019, Dynamical downscaling the impact of spring Western US land surface temperature on the 2015 flood extremes at the Southern Great Plains: effect of domain choice, dynamic cores and land surface parameterization: Climate Dynamics, v. 53, no. 1, p. 1039-1061.

Han, J., and Pan, H.-L., 2011, Revision of convection and vertical diffusion schemes in the NCEP Global Forecast System: Weather and Forecasting, v. 26, no. 4, p. 520-533.

He, J., Yang, K., Tang, W., Lu, H., Qin, J., Chen, Y., and Li, X., 2020, The first high-resolution meteorological forcing dataset for land process studies over China: Sci Data, v. 7, no. 1, p. 25.

Hong, S.-Y., Noh, Y., and Dudhia, J., 2006, A New Vertical Diffusion Package with an Explicit Treatment of Entrainment Processes: Monthly Weather Review, v. 134, no. 9, p. 2318-2341.

Hu, Q., and Feng, S., 2004, A Role of the Soil Enthalpy in Land Memory, v. 17, no. 18, p. 3633-3643.

lacono, M. J., Delamere, J. S., Mlawer, E. J., Shephard, M. W., Clough, S. A., and Collins, W. D., 2008, Radiative forcing by long-lived greenhouse gases: Calculations with the AER radiative transfer models: 
Jia, X., and Yang, S., 2013, Impact of the quasi-biweekly oscillation over the western North Pacific on East Asian subtropical monsoon during early summer: Journal of Geophysical Research-Atmospheres, v. 118, no. 10, p. 4421-4434.

Liu, Y., Xue, Y., and Li, Q., 2020, Investigation of the variability of nearsurface temperature anomaly and its causes over the Tibetan Plateau.: Journal of Geophysical Research-Atmospheres.

Mei, R., and Wang, G., 2011, Impact of Sea Surface Temperature and Soil Moisture on Summer Precipitation in the United States Based on Observational Data: Journal of Hydrometeorology, v. 12, no. 5, p. 1086-1099.

Merryfield, W. J., Baehr, J., Batté, L., Becker, E. J., Butler, A. H., Coelho, C. A. S., Danabasoglu, G., Dirmeyer, P. A., Doblas-Reyes, F. J., Domeisen, D. I. V., Ferranti, L., Ilynia, T., Kumar, A., Müller, W. A., Rixen, M., Robertson, A. W., Smith, D. M., Takaya, Y., Tuma, M., Vitart, F., White, C. J., Alvarez, M. S., Ardilouze, C., Attard, H., Baggett, C., Balmaseda, M. A., Beraki, A. F., Bhattacharjee, P. S., Bilbao, R., de Andrade, F. M., DeFlorio, M. J., Díaz, L. B., Ehsan, M. A., Fragkoulidis, G., Grainger, S., Green, B. W., Hell, M. C., Infanti, J. M., Isensee, K., Kataoka, T., Kirtman, B. P., Klingaman, N. P., Lee, J.-Y., Mayer, K., McKay, R., Mecking, J. V., Miller, D. E., Neddermann, N., Justin Ng, C. H., Ossó, A., Pankatz, K., Peatman, S., Pegion, K., Perlwitz, J., Recalde-Coronel, G. C., Reintges, A., Renkl, C., Solaraju-Murali, B., Spring, A., Stan, C., Sun, Y. Q., Tozer, C. R., Vigaud, N., Woolnough, S., and Yeager, S., 2020, Current and Emerging Developments in Subseasonal to Decadal Prediction: Bulletin of the American Meteorological Society, v. 101, no. 6, p. E869-E896.

Mo, K. C., Schemm, J.-K. E., and Yoo, S.-H., 2009, Influence of ENSO and the Atlantic Multidecadal Oscillation on Drought over the United States: Journal of Climate, v. 22, no. 22, p. 5962-5982.

Pu, B., Fu, R., Dickinson, R. E., and Fernando, D. N., 2016, Why do summer droughts in the Southern Great Plains occur in some La Nina years but not others?: Journal of Geophysical Research-Atmospheres, v. 121 , no. 3, p. 1120-1137.

Rajagopalan, B., Cook, E., Lall, U., and Ray, B. K., 2000, Spatiotemporal variability of ENSO and SST teleconnections to summer drought over the United States during the twentieth century: Journal of Climate, v. 13 , no. 24 , p. $4244-4255$.

Scaife, A. A., Kucharski, F., Folland, C. K., Kinter, J., Broennimann, S., Fereday, D., Fischer, A. M., Grainger, S., Jin, E. K., Kang, I. S., Knight, J. R., Kusunoki, S., Lau, N. C., Nath, M. J., Nakaegawa, T., Pegion, P., Schubert, S., Sporyshev, P., Syktus, J., Yoon, J. H., Zeng, N., and Zhou, T., 2009, The CLIVAR C20C project: selected twentieth century climate events: Climate Dynamics, v. 33, no. 5, p. 603-614.

Schubert, S., Gutzler, D., Wang, H., Dai, A., Delworth, T., Deser, C., Findell, K., Fu, R., Higgins, W., Hoerling, M., Kirtman, B., Koster, R., Kumar, A., Legler, D., Lettenmaier, D., Lyon, B., Magana, V., Mo, K., Nigam, S., Pegion, P., Phillips, A., Pulwarty, R., Rind, D., Ruiz-Barradas, A., Schemm, J., Seager, R., Stewart, R., Suarez, M., Syktus, J., Ting, M., Wang, C., Weaver, S., and Zeng, N., 2009, A US CLIVAR Project to Assess and Compare Loading [MathJax]/jax/output/CommonHTML/fonts/TeX/fontdata.js 
the Responses of Global Climate Models to Drought-Related SST Forcing Patterns: Overview and Results: Journal of Climate, v. 22, no. 19, p. 5251-5272.

Schubert, S. D., Suarez, M. J., Pegion, P. J., Koster, R. D., and Bacmeister, J. T., 2004, Causes of long-term drought in the US Great Plains: Journal of Climate, v. 17, no. 3, p. 485-503.

Seager, R., Goddard, L., Nakamura, J., Henderson, N., and Lee, D. E., 2014, Dynamical Causes of the 2010/11 Texas-Northern Mexico Drought*: Journal of Hydrometeorology, v. 15, no. 1, p. 39-68.

Shukla, R. P., Huang, B., Dirmeyer, P. A., and Kinter, J. L., 2019, The Influence of Summer Deep Soil Temperature on Early Winter Snow Conditions in Eurasia in the NCEP CFSv2 Simulation: Journal of Geophysical Research: Atmospheres, v. 124, no. 16, p. 9062-9077.

Skamarock, W. C., Klemp, J. B., Dudhia, J., Gill, D. O., Barker, D. M., Wang, W., and Powers, J. G., 2008, A description of the Advanced Research WRF version 3. NCAR Technical note-475+ STR.

Su, Z., Wen, J., Dente, L., van der Velde, R., Wang, L., Ma, Y., Yang, K., and Hu, Z., 2011, The Tibetan Plateau observatory of plateau scale soil moisture and soil temperature (Tibet-Obs) for quantifying uncertainties in coarse resolution satellite and model products: Hydrology and Earth System Sciences, v. 15, no. 7, p. 2303-2316.

Ting, M. F., and Wang, H., 1997, Summertime US precipitation variability and its relation to Pacific sea surface temperature: Journal of Climate, v. 10, no. 8, p. 1853-1873.

Trenberth, K. E., Branstator, G. W., and Arkin, P. A., 1988, ORIGINS OF THE 1988 NORTH-AMERICAN DROUGHT: Science, v. 242, no. 4886, p. 1640-1645.

Wang, B., Bao, Q., Hoskins, B., Wu, G., and Liu, Y., 2008, Tibetan plateau warming and precipitation changes in East Asia: Geophysical Research Letters, v. 35, no. 14.

Wu, G., Liu, Y., Wang, T., Wan, R., Liu, X., Li, W., Wang, Z., Zhang, Q., Duan, A., and Liang, X., 2007, The influence of mechanical and thermal forcing by the Tibetan Plateau on Asian climate: Journal of Hydrometeorology, v. 8, no. 4, p. 770-789.

Wu, Y., Liu, Y., Li, J., Bao, Q., He, B., Wang, L., Wang, X., and Li, J., 2021, Analysis of surface temperature

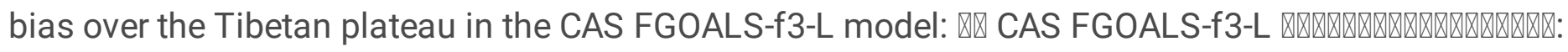
Atmospheric and Oceanic Science Letters, v. 14, no. 1, p. 100012.

Xue, Y., Boone, A., and Yao, T., 2019, Remote effects of high elevation land surface temperature on S2S precipitation prediction: First Workshop on LS4P and TPEMIP: GEWEX News Querterly Newsletter.

Xue, Y., De Sales, F., Lau, W. K. M., Boone, A., Kim, K.-M., Mechoso, C. R., Wang, G., Kucharski, F., Schiro, K., Hosaka, M., Li, S., Druyan, L. M., Sanda, I. S., Thiaw, W., Zeng, N., Comer, R. E., Lim, Y.-K., Mahanama, S., Loading [MathJax]/jax/output/CommonHTML/fonts/TeX/fontdata.js yer, P., Ruby Leung, L., Kalnay, E., Kitoh, A., Lu, 
C.-H., Mahowald, N. M., and Zhang, Z., 2016a, West African monsoon decadal variability and surfacerelated forcings: second West African Monsoon Modeling and Evaluation Project Experiment (WAMME II): Climate Dynamics, v. 47, no. 11, p. 3517-3545.

Xue, Y., Diallo, I., Li, W., David Neelin, J., Chu, P. C., Vasic, R., Guo, W., Li, Q., Robinson, D. A., Zhu, Y., Fu, C., and Oaida, C. M., 2018, Spring Land Surface and Subsurface Temperature Anomalies and Subsequent Downstream Late Spring-Summer Droughts/Floods in North America and East Asia: Journal of Geophysical Research: Atmospheres, v. 123, no. 10, p. 5001-5019.

Xue, Y., Oaida, C. M., Diallo, I., Neelin, J. D., Li, S., De Sales, F., Gu, Y., Robinson, D. A., Vasic, R., and Yi, L., 2016b, Spring land temperature anomalies in northwestern US and the summer drought over Southern Plains and adjacent areas: Environmental Research Letters, v. 11, no. 4, p. 044018.

Xue, Y., Yao, T., Boone, A. A., Diallo, I., Liu, Y., Zeng, X., Lau, W. K. M., Sugimoto, S., Tang, Q., Pan, X., van Oevelen, P. J., Klocke, D., Koo, M. S., Lin, Z., Takaya, Y., Sato, T., Ardilouze, C., Saha, S. K., Zhao, M., Liang, X. Z., Vitart, F., Li, X., Zhao, P., Neelin, D., Guo, W., Yu, M., Qian, Y., Shen, S. S. P., Zhang, Y., Yang, K., Leung, R., Yang, J., Qiu, Y., Brunke, M. A., Chou, S. C., Ek, M., Fan, T., Guan, H., Lin, H., Liang, S., Materia, S., Nakamura, T., Qi, X., Senan, R., Shi, C., Wang, H., Wei, H., Xie, S., Xu, H., Zhang, H., Zhan, Y., Li, W., Shi, X., Nobre, P., Qin, Y., Dozier, J., Ferguson, C. R., Balsamo, G., Bao, Q., Feng, J., Hong, J., Hong, S., Huang, H., Ji, D., Ji, Z., Kang, S., Lin, Y., Liu, W., Muncaster, R., Pan, Y., Peano, D., de Rosnay, P., Takahashi, H. G., Tang, J., Wang, G., Wang, S., Wang, W., Zhou, X., and Zhu, Y., 2021, Impact of Initialized Land Surface Temperature and Snowpack on Subseasonal to Seasonal Prediction Project, Phase I (LS4P-I): Organization and Experimental design: Geosci. Model Dev. Discuss., v. 2021, p. 1-58.

Yanai, M. H., Li, C. F., and Song, Z. S., 1992, SEASONAL HEATING OF THE TIBETAN PLATEAU AND ITS EFFECTS ON THE EVOLUTION OF THE ASIAN SUMMER MONSOON: Journal of the Meteorological Society of Japan, v. 70, no. 1B, p. 319-351.

Yang, K., Chen, Y.-Y., and Qin, J., 2009, Some practical notes on the land surface modeling in the Tibetan Plateau: Hydrology Earth System SciencesHydrology, v. 13, no. 5, p. 687-701.

Yang, K., and Zhang, J., 2016, Spatiotemporal characteristics of soil temperature memory in China from observation: Theoretical and Applied Climatology, v. 126, no. 3, p. 739-749.

Yao, T., Xue, Y., Chen, D., Chen, F., Thompson, L., Cui, P., Koike, T., Lau, W. K. M., Lettenmaier, D., Mosbrugger, V., Zhang, R., Xu, B., Dozier, J., Gillespie, T., Gu, Y., Kang, S., Piao, S., Sugimoto, S., Ueno, K., Wang, L., Wang, W., Zhang, F., Sheng, Y., Guo, W., Ailikun, Yang, X., Ma, Y., Shen, S. S. P., Su, Z., Chen, F., Liang, S., Liu, Y., Singh, V. P., Yang, K., Yang, D., Zhao, X., Qian, Y., Zhang, Y., and Li, Q., 2019, Recent Third Pole's Rapid Warming Accompanies Cryospheric Melt and Water Cycle Intensification and Interactions between Monsoon and Environment: Multidisciplinary Approach with Observations, Modeling, and Analysis: Bulletin of the American Meteorological Society, v. 100, no. 3, p. 423-444. 
Ye, D. Z., 1981, SOME CHARACTERISTICS OF THE SUMMER CIRCULATION OVER THE QINGHAI-XIZANG (TIBET) PLATEAU AND ITS NEIGHBORHOOD: Bulletin of the American Meteorological Society, v. 62, no. 1, p. 14-19.

Zeng, X., and Decker, M., 2009, Improving the Numerical Solution of Soil Moisture?Based Richards Equation for Land Models with a Deep or Shallow Water Table: Journal of Hydrometeorology, v. 10, no. 1, p. 308-319.

\section{Tables}

Table.1 Model structure of SSiB, CLM and Noah-MP.

\begin{tabular}{cccc}
\hline Model & Number & Soil layers & Ref \\
\hline SSiB & 3 & $0,0.05,1.05$ & Xue et al. (1991) \\
CLM & 10 & $0.01,0.03,0.06,0.12,0.21,0.37,0.62,1.04,1.73$, & Oleson et al. \\
& & 2.86 & (2010) \\
\hline $\begin{array}{c}\text { Noah- } \\
\text { MP }\end{array}$ & 4 & $0.05,0.25,0.7,1.5$ & Niu et al. (2011) \\
\hline
\end{tabular}

Table.2 Spatial correlation coefficient (Cor) and mean bias of the simulated $\mathrm{T} 2 \mathrm{~m}$ (unit: ${ }^{\circ} \mathrm{C}$ ) and precipitation (unit: $\mathrm{mm} /$ day) over the Tibetan Plateau in the control experiments with different land models.

\begin{tabular}{ccccc}
\hline Model & \multicolumn{2}{c}{ T2m } & \multicolumn{2}{c}{ Precipitation } \\
\cline { 2 - 5 } & Cor & Bias & Cor & Bias \\
\hline SSiB & 0.85 & 2.87 & 0.62 & 2.71 \\
CLM & 0.88 & 1.58 & 0.66 & 2.71 \\
Noah-MP & 0.87 & 1.16 & 0.62 & 3.11 \\
\hline
\end{tabular}

Table. 3 Statistics of T2m/surface/soil memories (unit: days) over the Tibetan Plateau in the $+5^{\circ} \mathrm{C}$ and $-5^{\circ} \mathrm{C}$ experiment with different land models, in which "Range" refers to the interquartile range. The soil memories are at the layers of $0.05,0.5$, and $1.0 \mathrm{~m}$ 


\begin{tabular}{|c|c|c|c|c|c|c|c|}
\hline \multirow[t]{2}{*}{ Model } & \multirow[t]{2}{*}{ Variable } & \multicolumn{3}{|c|}{$+5^{\circ} \mathrm{C}$} & \multicolumn{3}{|c|}{$-5^{\circ} \mathrm{C}$} \\
\hline & & Mean & Median & Range & Mean & Median & Range \\
\hline \multirow[t]{5}{*}{ SSiB } & $\mathrm{T} 2 \mathrm{~m}$ & 19.9 & 19.2 & $14.3-24.8$ & 22.6 & 21.8 & $15.8-29.0$ \\
\hline & Surface & 19.8 & 19.2 & $14.2-24.7$ & 22.5 & 21.7 & $15.7-28.8$ \\
\hline & $0.05 \mathrm{~m}$ & 21.1 & 20.2 & $15.5-25.8$ & 24.0 & 22.8 & $16.8-30.5$ \\
\hline & $0.5 \mathrm{~m}$ & 39.1 & 38.4 & $34.2-43.0$ & 45.2 & 44.4 & $39.3-50.9$ \\
\hline & $1.0 \mathrm{~m}$ & 59.0 & 58.2 & $53.5-63.7$ & 68.8 & 68.6 & $61.8-75.4$ \\
\hline \multirow[t]{5}{*}{ CLM } & $\mathrm{T} 2 \mathrm{~m}$ & 13.0 & 10.8 & $7.2-15.8$ & 15.7 & 12.0 & $7.8-18.8$ \\
\hline & Surface & 6.6 & 5.2 & $3.5-8.2$ & 10.8 & 8.2 & $4.0-14.3$ \\
\hline & $0.05 \mathrm{~m}$ & 51.6 & 19.9 & $9.2-123.0$ & 54.0 & 27.8 & $17.8-123.0$ \\
\hline & $0.5 \mathrm{~m}$ & 101.6 & 114.9 & $83.3-123.0$ & 83.3 & 90.3 & $44.7-123.0$ \\
\hline & $1.0 \mathrm{~m}$ & 111.0 & 122.5 & $110.2-123.0$ & 97.8 & 117.2 & 70.6-123.0 \\
\hline \multirow[t]{5}{*}{ Noah-MP } & $\mathrm{T} 2$ & 6.1 & 4.8 & $3.2-8.0$ & 7.3 & 5.7 & $3.5-10.3$ \\
\hline & Surface & 6.4 & 4.8 & $2.8-8.7$ & 7.0 & 5.2 & $3.0-9.8$ \\
\hline & $0.05 \mathrm{~m}$ & 15.8 & 12.0 & $8.2-20.3$ & 15.8 & 12.0 & $7.7-19.0$ \\
\hline & $0.5 \mathrm{~m}$ & 85.2 & 89.7 & 71.5-103.2 & 48.9 & 31.9 & $25.7-73.5$ \\
\hline & $1.0 \mathrm{~m}$ & 104.5 & 118.8 & $92.2-123.0$ & 62.3 & 46.5 & $38.8-88.0$ \\
\hline
\end{tabular}

\section{Figures}

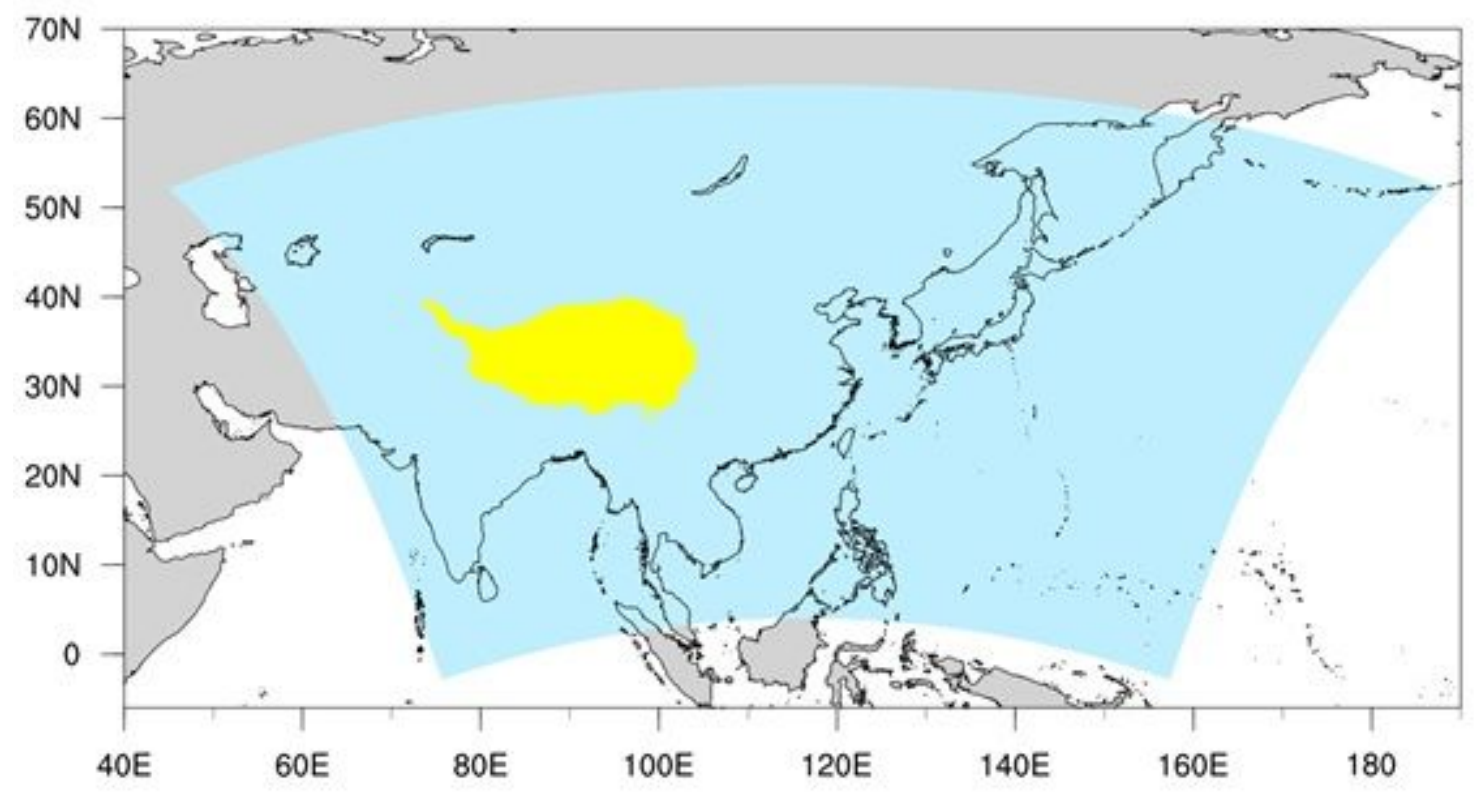

Figure 1

Domain of the WRF model (the blue area) and the Tibetan Plateau (the yellow area) 


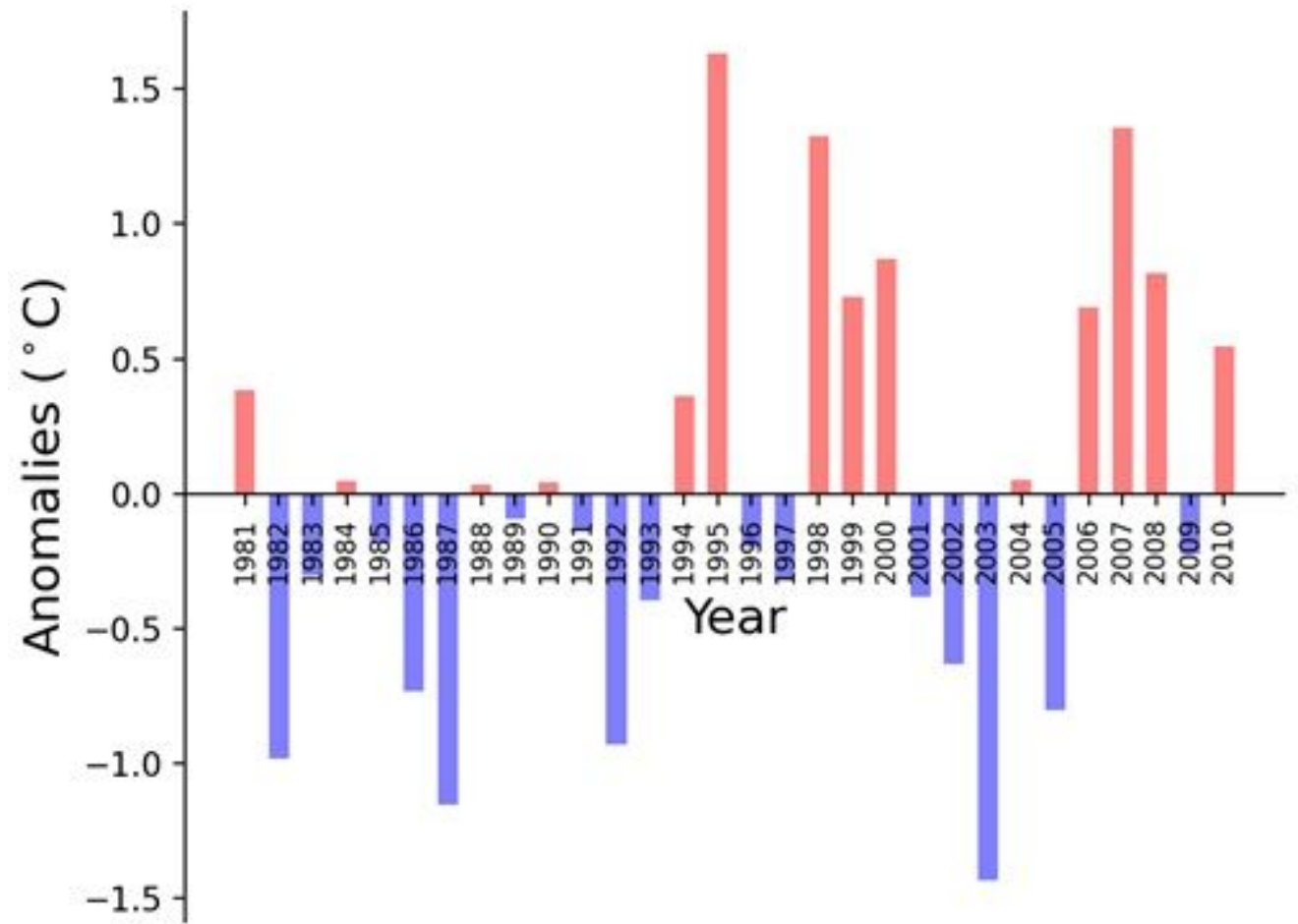

Figure 2

May T2m anomaly averaged over the Tibetan Plateau during 1981-2010 relative to the time mean based on the China Meteorological Forcing Dataset.

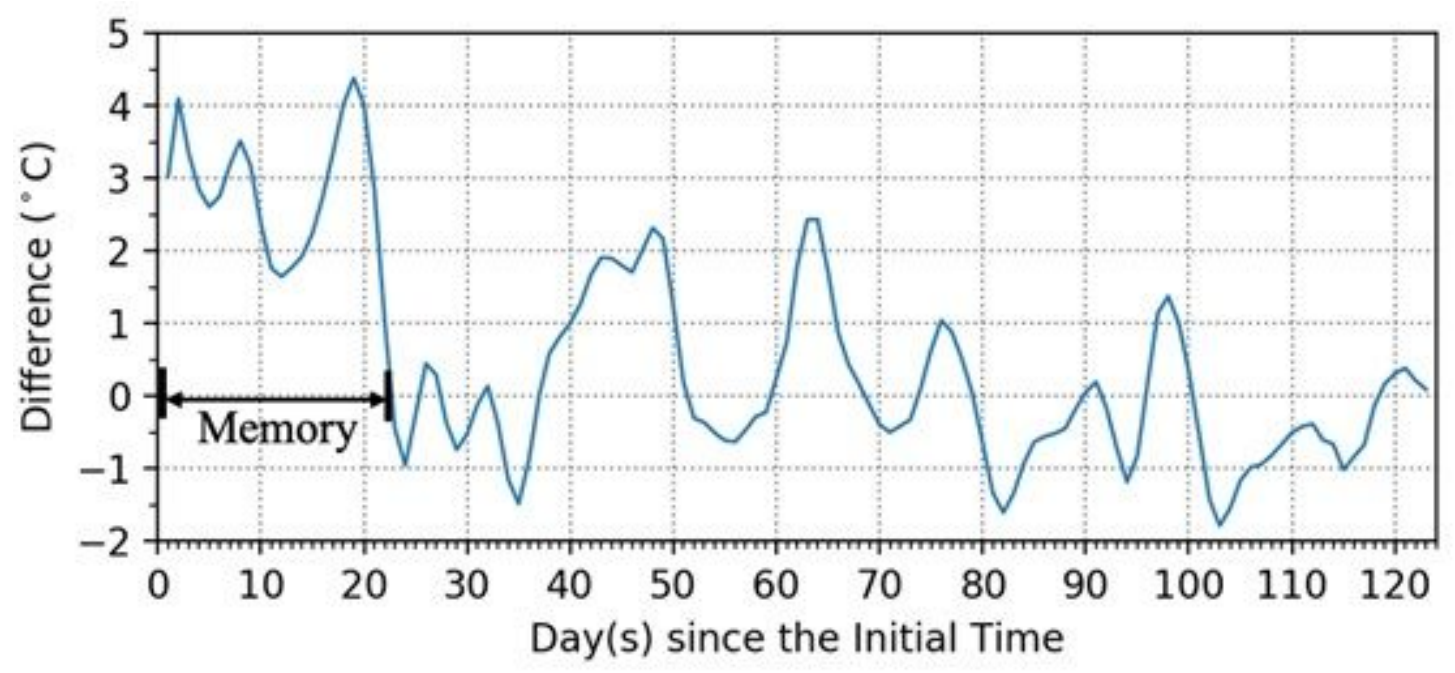

Figure 3

Time series of the differences in daily soil temperature at the layer of $0.25 \mathrm{~m}$ between the control and $+5^{\circ} \mathrm{C}$ experiment with the land model of Noah-MP on a randomly selected model grid $\left(35.3^{\circ} \mathrm{N}, 88.4^{\circ} \mathrm{E}\right)$ during 2003. The three-point smoothing method is applied to erase the high-frequency oscillations in the time series. 
(a)T2m,CMFD

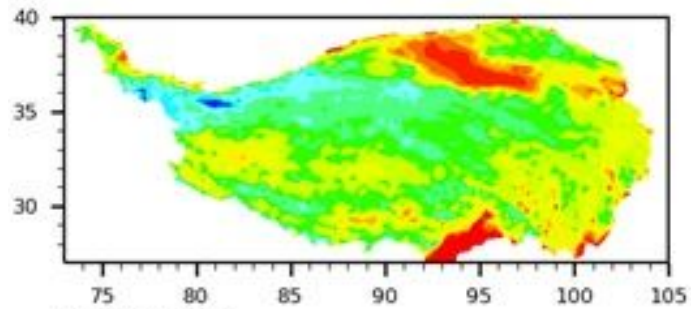

(b)T2m,SSIB

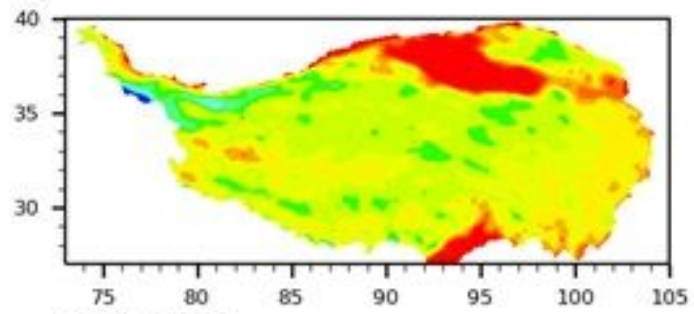

(c) T2m,CLM

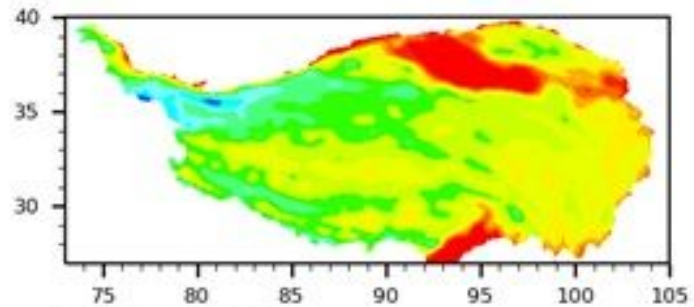

(d)T2m,Noah-MP

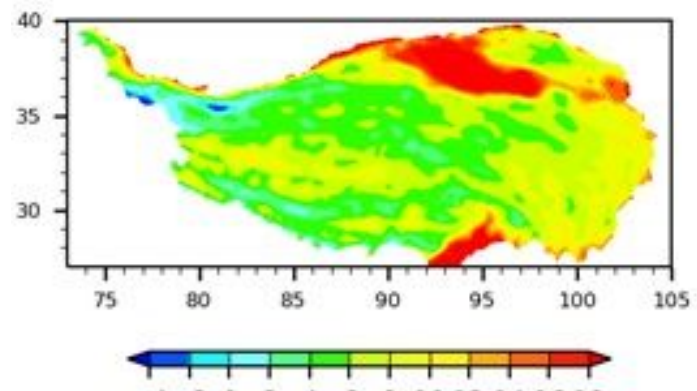

$\begin{array}{lllllllll}-4-2 & 0 & 2 & 4 & 6 & 8 & 1012141618\end{array}$

unit: ( ${ }^{\circ} \mathrm{C}$ )
(e)Pre,CMFD

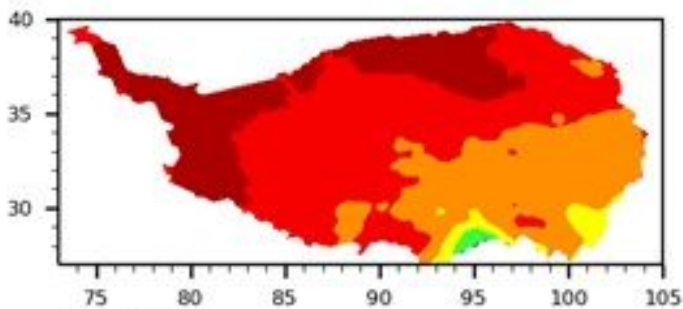

(f)Pre,SSiB

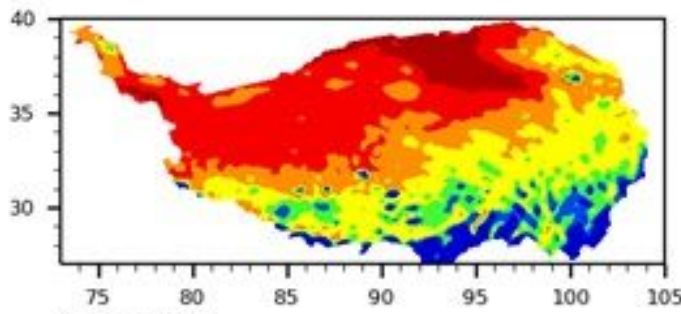

(g)Pre,CLM

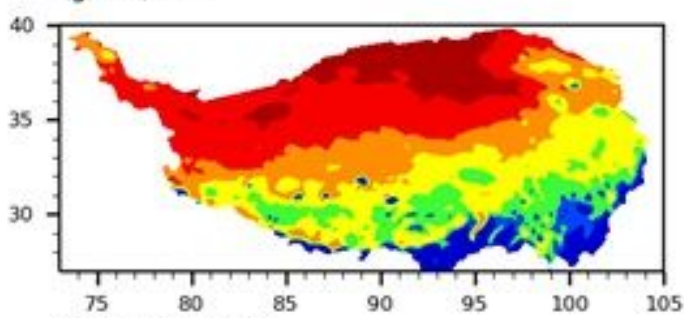

(h)Pre,Noah-MP

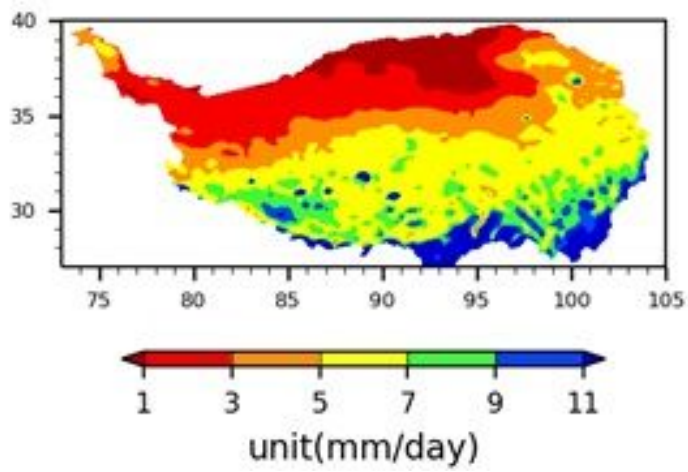

Figure 4

Spatial distribution of time averaged $\mathrm{T} 2 \mathrm{~m}$ (unit: ${ }^{\circ} \mathrm{C}$ ) and precipitation (Pre, unit: $\mathrm{mm} /$ day) in the validation data (CMFD) and the control experiments with different land models during May - August in the selected year $(1987,1991,1996,1998,2003$, and 2007) 
(a)SSiB

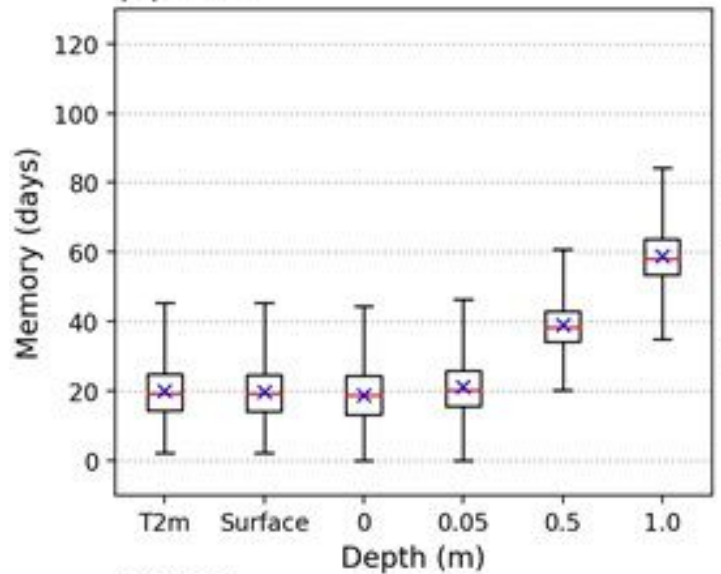

(c)CLM
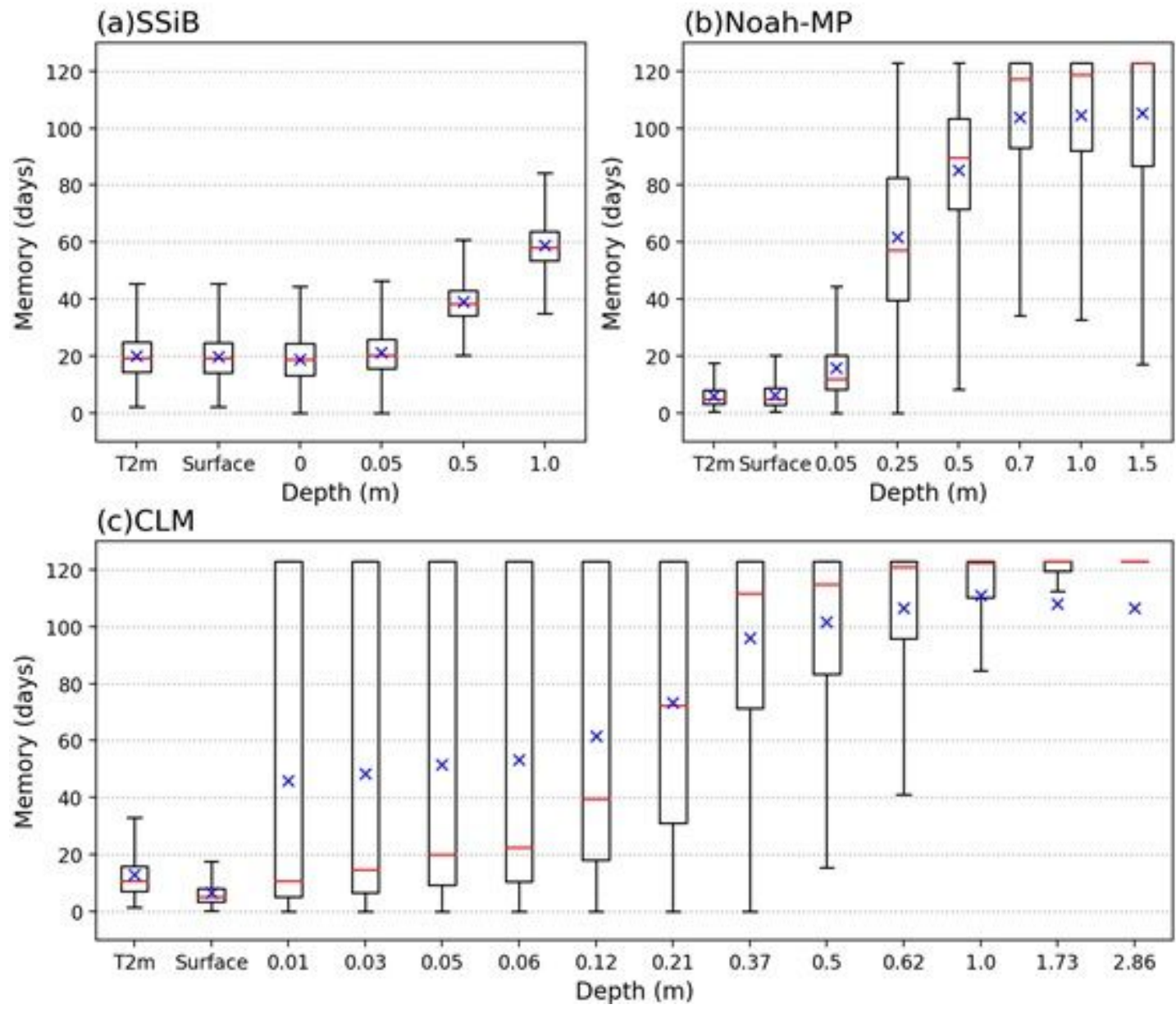

Figure 5

Boxplots of T2m/surface/soil memories (units: days) over the Tibetan Plateau in the $+5^{\circ} \mathrm{C}$ experiments with different land models, in which the digitals along the x-axis are the depths of the soil layers. In addition, the markers " $x$ " indicate the means and the upper (lower) whiskers extent to the last datum less (greater) than Q3+2×IQR (Q1-2×IQR). Q3(Q1) is the third (first) quartile. IQR is the interquartile range (Q3Q1). The outliers are not shown. 

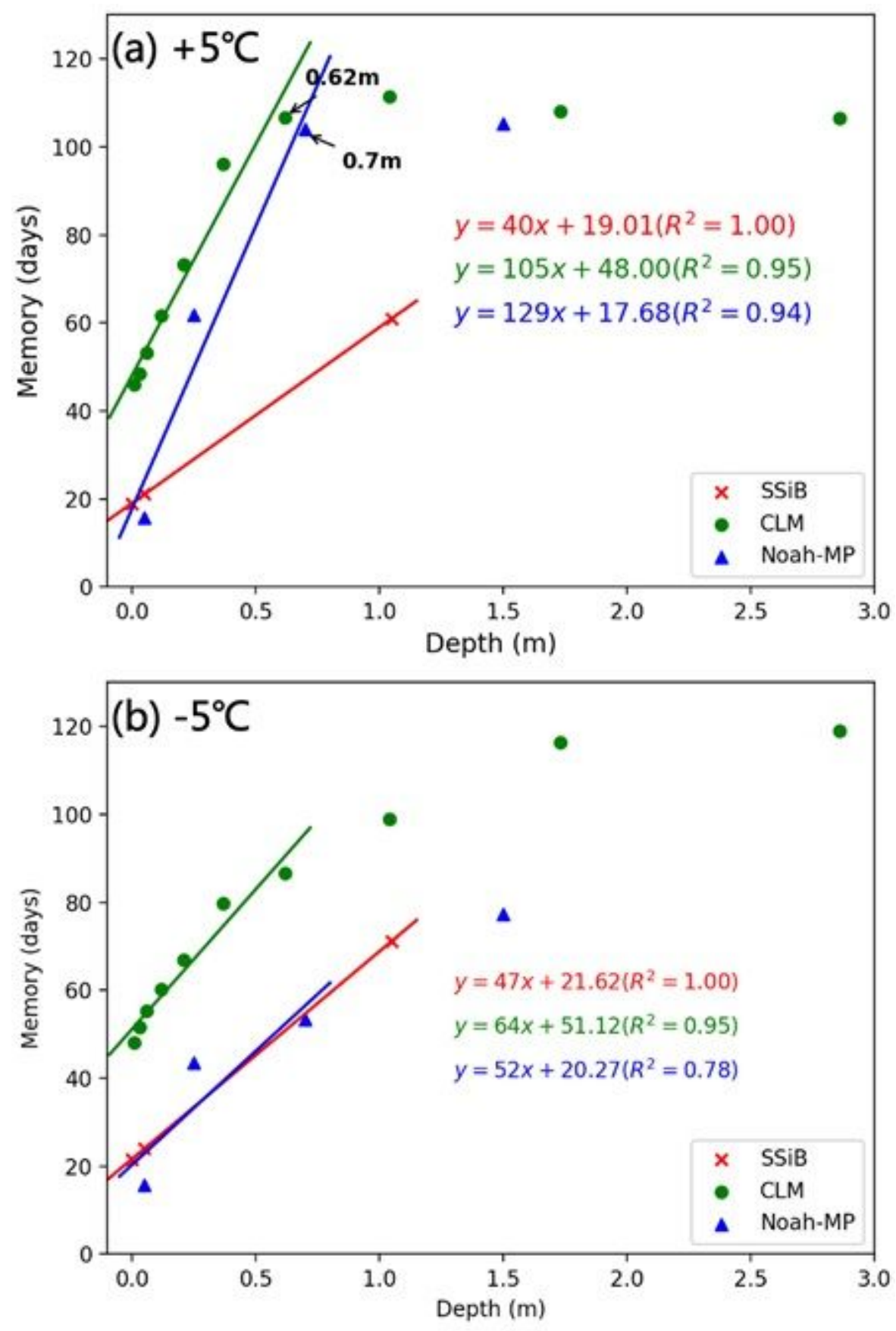

Figure 6

Scatterplots of regional mean soil memory and original soil layers in the $(a)+5^{\circ} \mathrm{C}$ and $(b)-5^{\circ} \mathrm{C}$ experiment with different land models. The regional mean soil memories at the specified layers in each land model are linearly fitted with the soil depth (lines). When doing the fitting, we used the layer of $0.62 \mathrm{~m}$ and above in CLM, the layer of $0.7 \mathrm{~m}$ and above in Noah-MP, and all the layers in SSiB. 
(a)SSiB@T2m

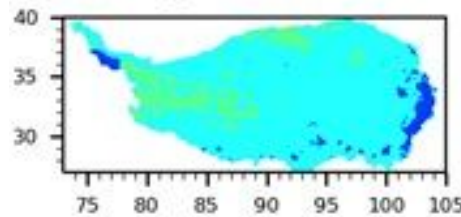

(d)SSIB@LST

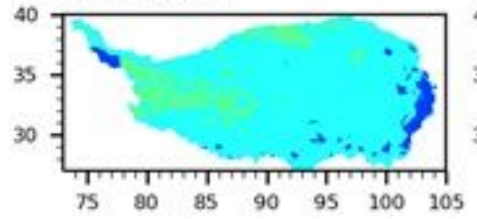

(g)SSiB@0.05m

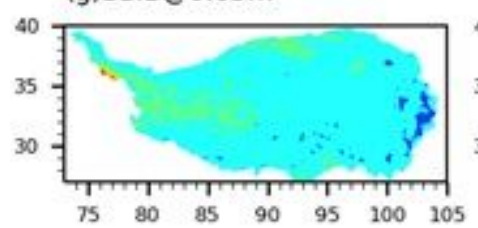

(j)SSiB@0.5m

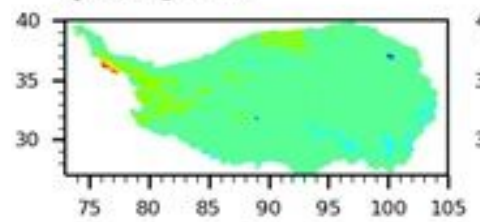

(m)SSiB@1.0m

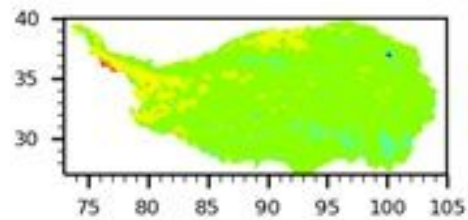

(b)CLM@T2m

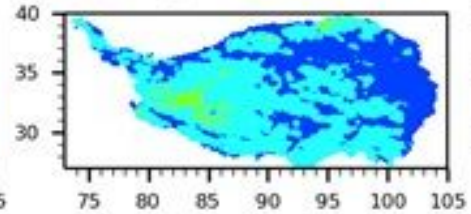

(e)CLM@LST

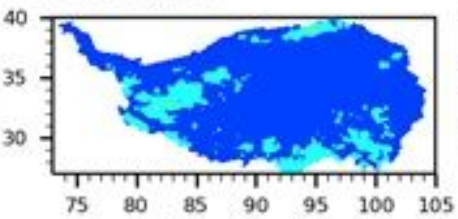

(h)CLM@0.05m

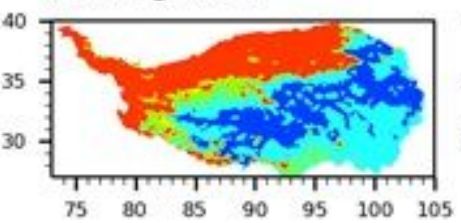

(k)CLM@0.5m

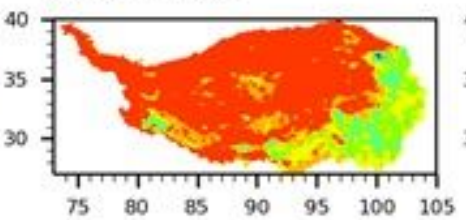

(n)CLM@1.0m

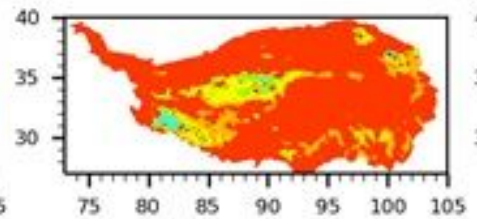

(c)Noah-MP@T2m

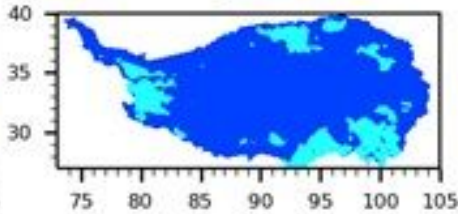

(f)Noah-MP@LST

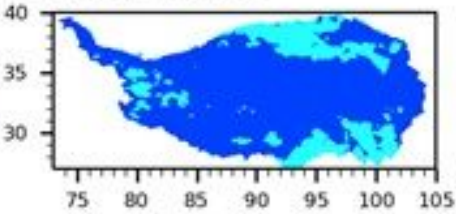

(i)Noah-MP@0.05m

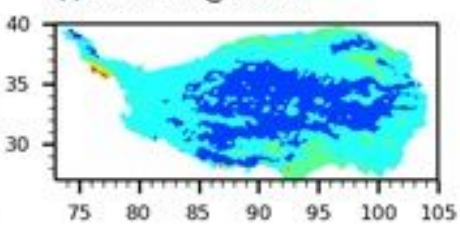

(I)Noah-MP@0.5m

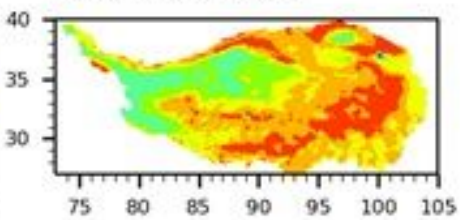

(o)Noah-MP@1.0m

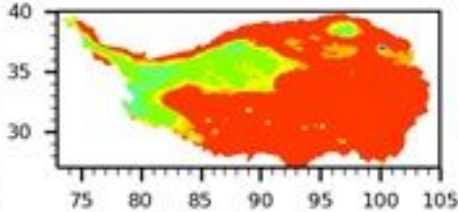

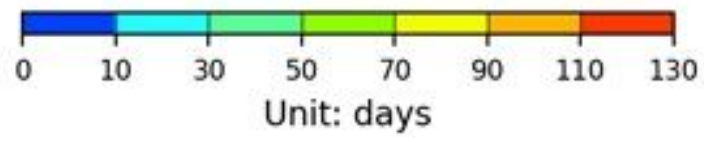

Figure 7

Spatial distribution of T2m/surface/soil memories (unit: days) in the Tibetan Plateau in the $+5^{\circ} \mathrm{C}$ experiments with different land models. The soil memories are at the layers of $0.05,0.5$, and $1.0 \mathrm{~m}$. 
(a) $\mathrm{SSiB},+5^{\circ} \mathrm{C}$

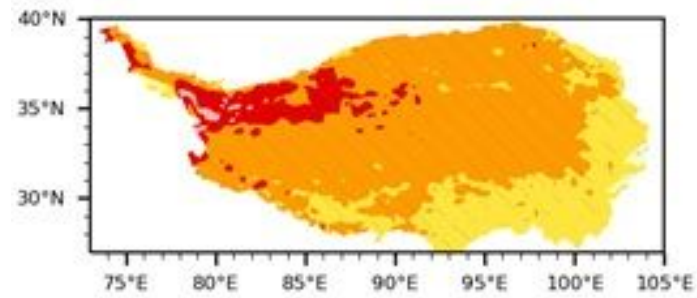

(c) CLM, $+5^{\circ} \mathrm{C}$

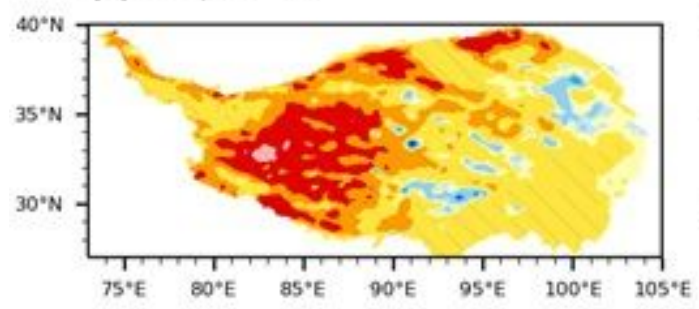

(e)Noah-MP, $+5^{\circ} \mathrm{C}$

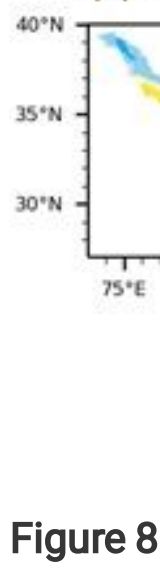

Spatial distribution of the differences (unit: ${ }^{\circ} \mathrm{C}$ ) in May $\mathrm{T} 2 \mathrm{~m}$ between the control and $\pm 5^{\circ} \mathrm{C}$ experiment with different land models. The slashed areas indicate the differences passed paired sample T-test with at the $95 \%$ confidence level.
(b)SSiB, $-5^{\circ} \mathrm{C}$

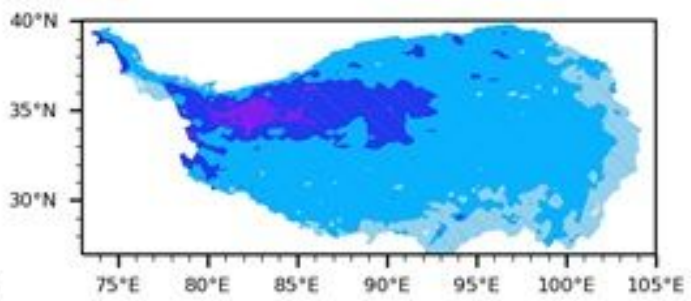

(d) CLM, $-5^{\circ} \mathrm{C}$

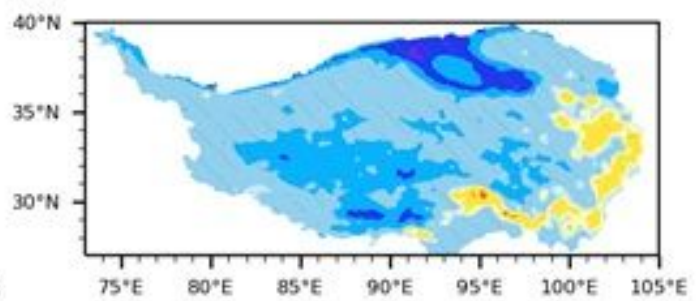

(f) Noah-MP, $-5^{\circ} \mathrm{C}$

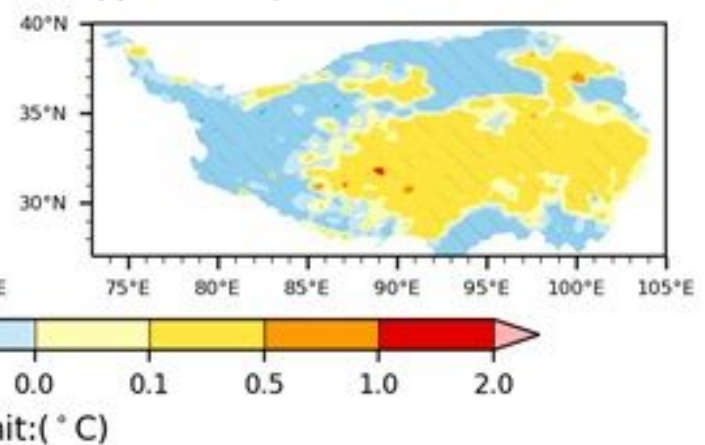



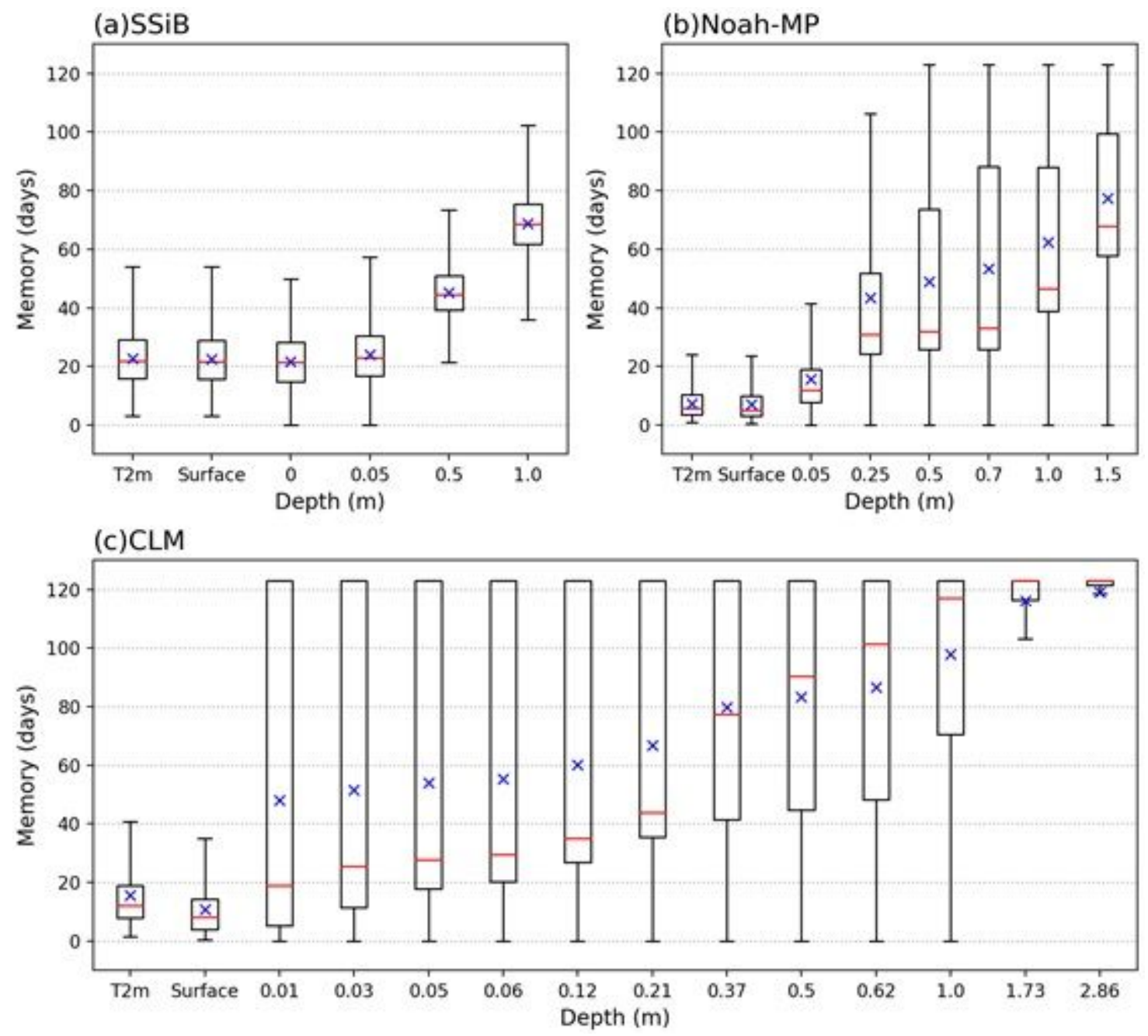

Figure 9

Similar to Fig. 5 , but in the $-5^{\circ} \mathrm{C}$ experiments. 
(a)SSiB@T2m

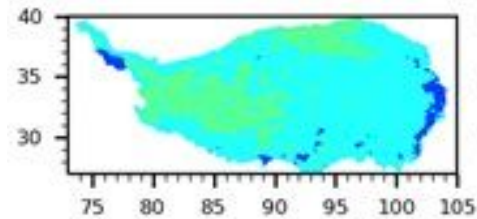

(d)SSIB@LST

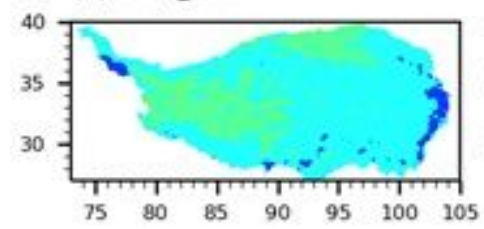

(g)SSiB@0.05m

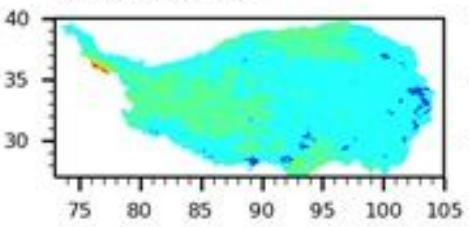

(j)SSiB@0.5m

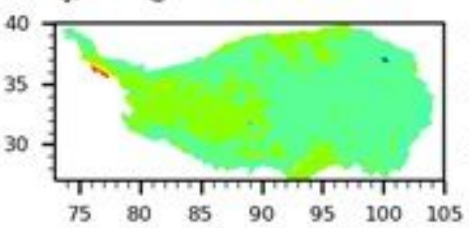

(m)SSiB@1.0m

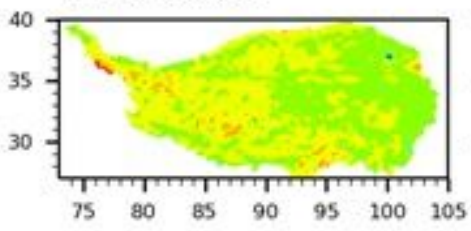

(b)CLM@T2m

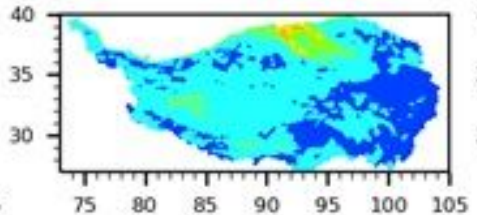

(e)CLM@LST

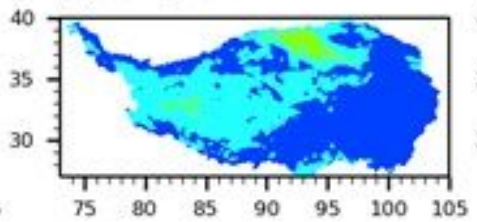

(h)CLM@0.05m

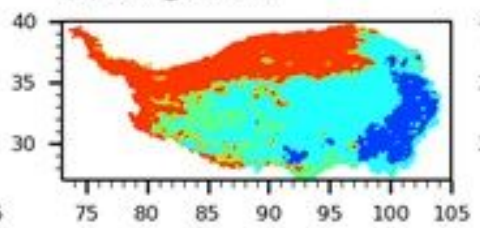

(k)CLM@0.5m

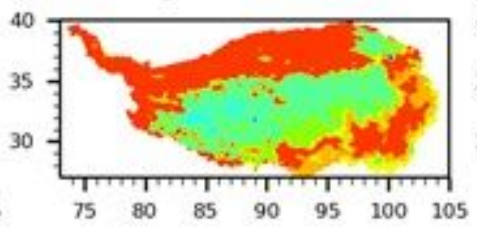

(n)CLM@1.0m

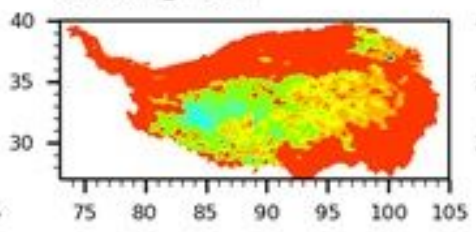

(o)Noah-MP@1.0m

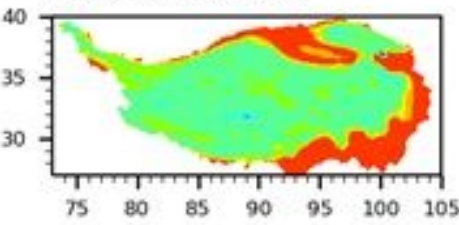

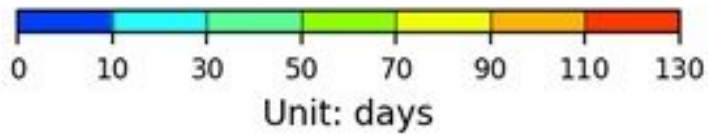

Figure 10

Similar to Fig. 6 , but in the $-5^{\circ} \mathrm{C}$ experiments. 
(a)

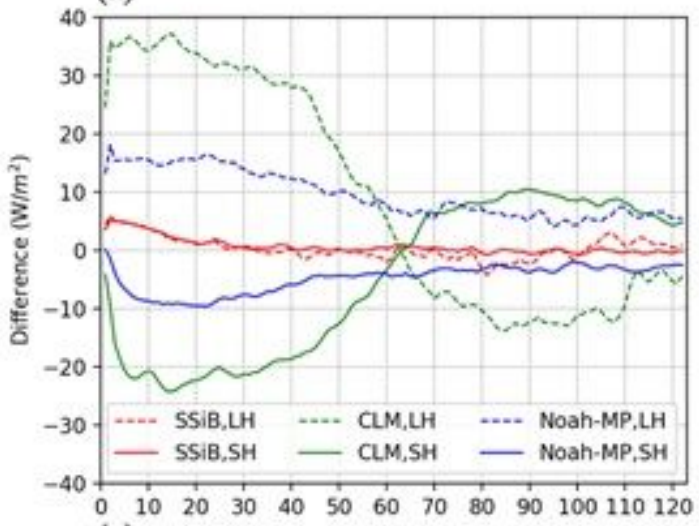

(c)

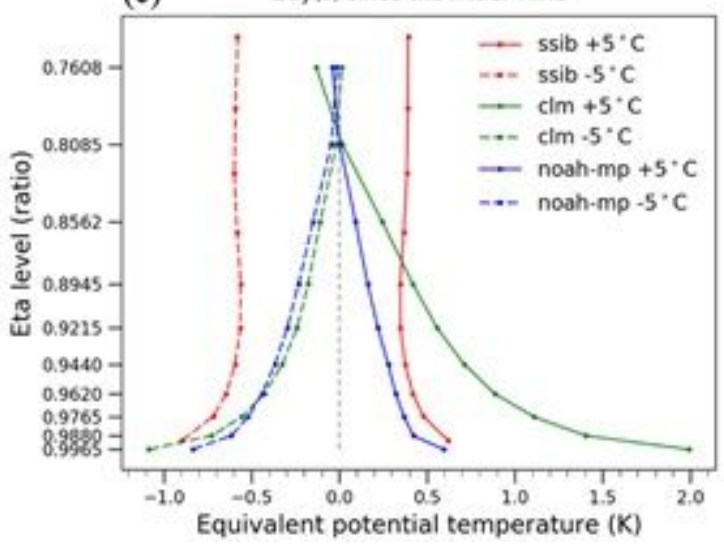

(b)

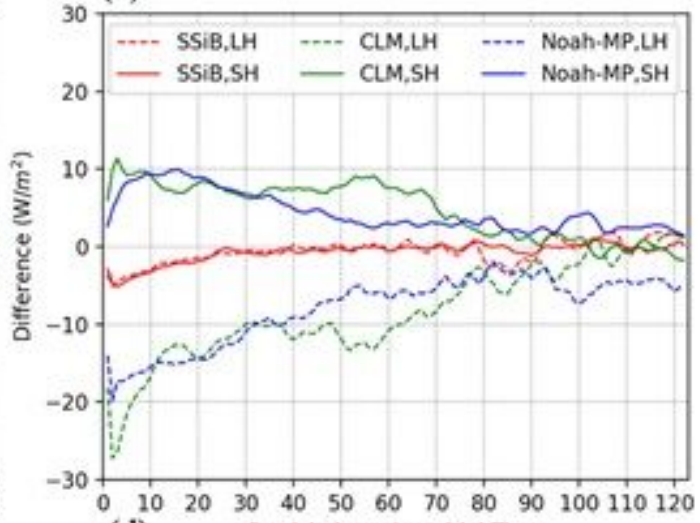

(d)

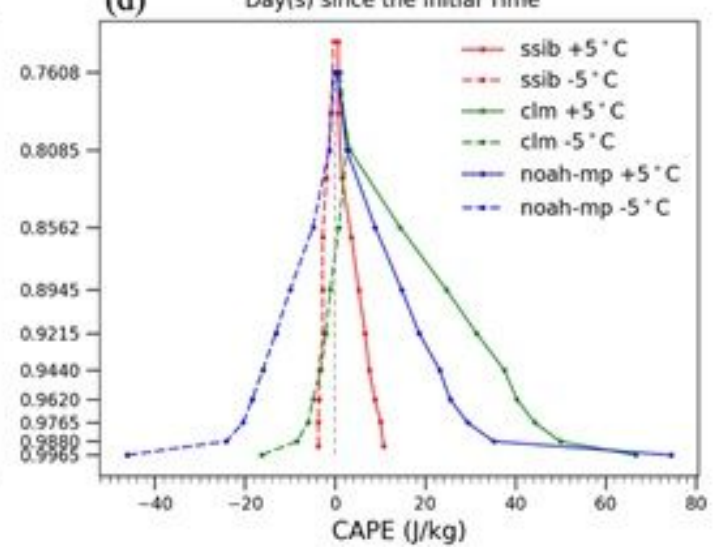

\section{Figure 11}

(a) Time series of the differences in daily sensible/latent heat (SH/LH, unit: W/m2) averaged over the Tibetan Plateau between the control and $+5^{\circ} \mathrm{C}$ experiment with different land models; (b) same as (a) but between the control and $-5^{\circ} \mathrm{C}$ experiments; (c) differences in the vertical profile of the May equivalent potential temperature (EPT, unit: $\mathrm{K}$ ) on the eta levels between the control and $\pm 5^{\circ} \mathrm{C}$ experiment with different land models; (d) same as (c) but for the May convective available potential energy (CAPE, unit: $\mathrm{J} / \mathrm{kg})$. 
(a)SSiB, LH

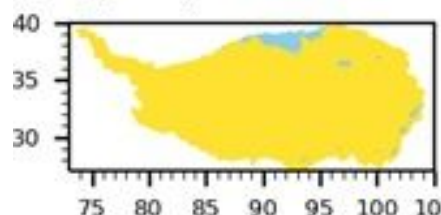

(d) $\mathrm{SSiB}, \mathrm{SH}$

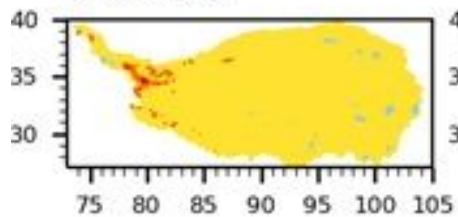

(g)SSiB,pre

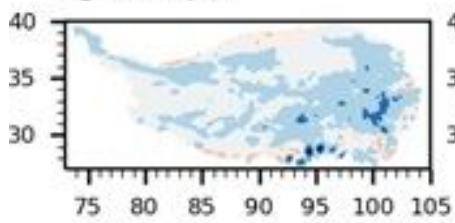

(j)SSIB,SMOIS

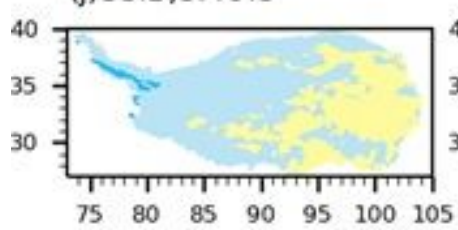

(b) CLM, LH

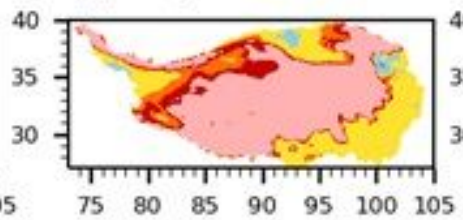

(e)CLM,SH

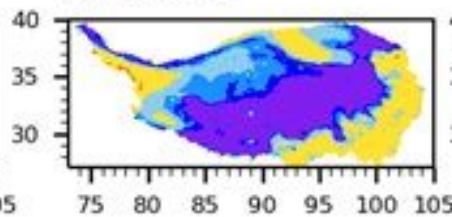

(h)CLM,pre

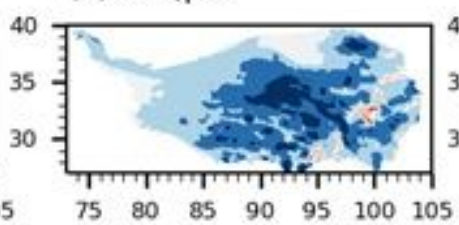

(k)CLM,SMOIS

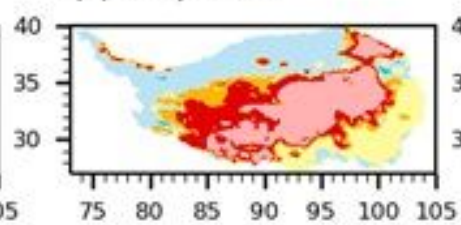

(c)Noah-MP,LH

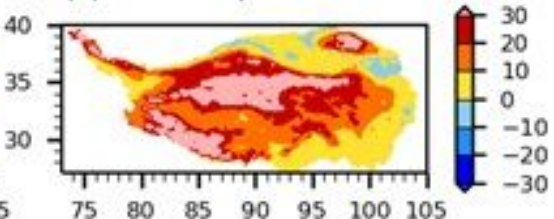

(f)Noah-MP,SH

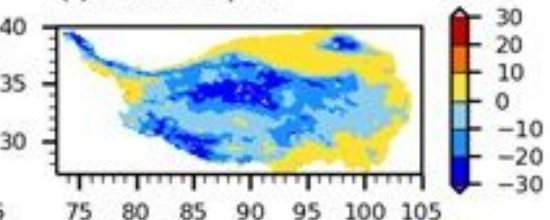

(i)Noah-MP,pre

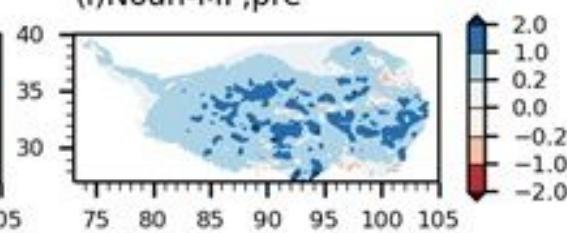

(I)Noah-MP,SMOIS

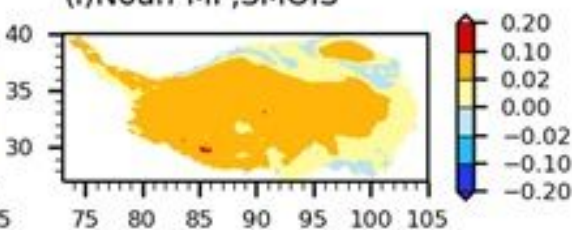

Figure 12

Differences in May latent heat flux ( $\mathrm{LH}$, unit: $\mathrm{W} / \mathrm{m} 2)$, sensible heat flux (SH, unit: $\mathrm{W} / \mathrm{m} 2)$, precipitation (pre, unit: $\mathrm{mm} /$ day), and soil moisture at $0.05 \mathrm{~m}$ (SMOIS, unit: $\mathrm{m} 3 / \mathrm{m} 3$ ) in the $+5^{\circ} \mathrm{C}$ experiment with different land models. 
(a) SSiB,LH

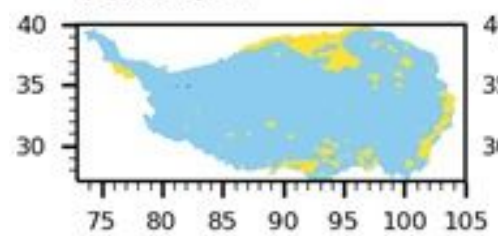

(d) $\mathrm{SSiB}, \mathrm{SH}$

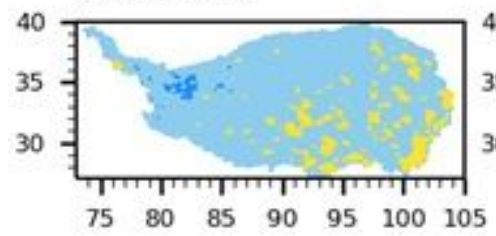

(g)SSiB,pre

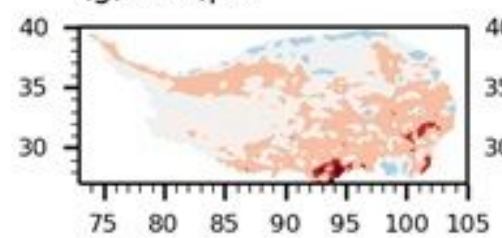

(j)SSiB,SMOIS

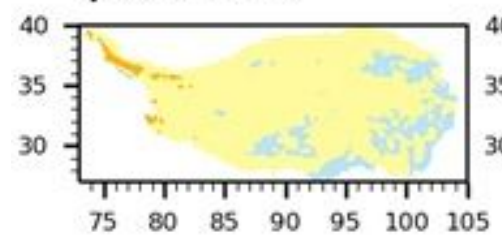

(b) CLM,LH

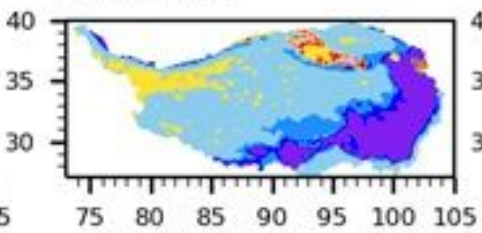

(e)CLM,SH

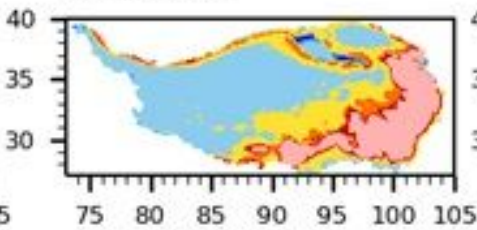

(h)CLM,pre

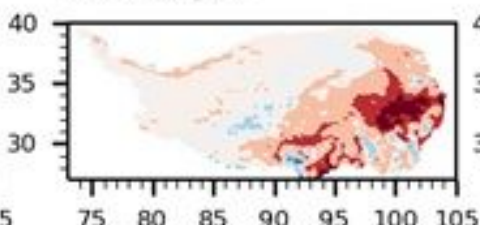

(k)CLM,SMOIS

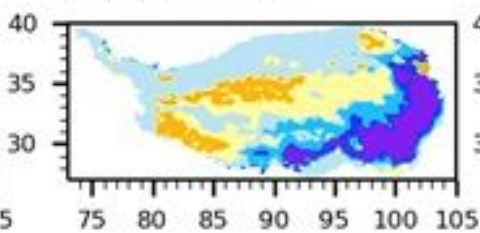

(c)Noah-MP,LH

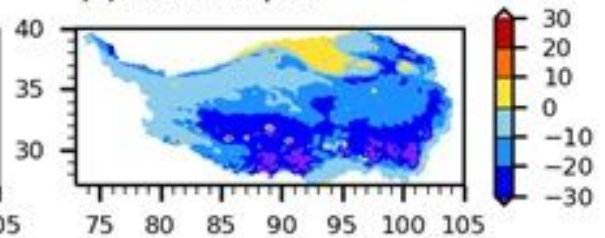

(f)Noah-MP,SH

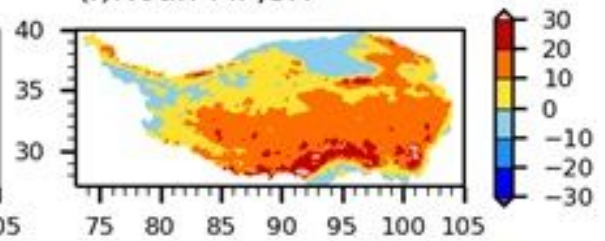

(i)Noah-MP,pre

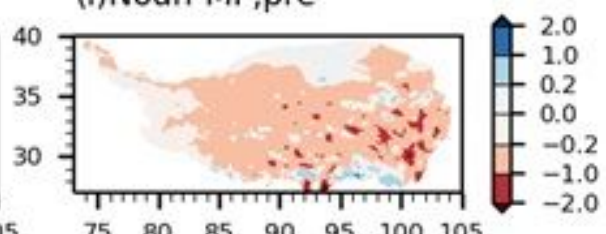

(I)Noah-MP,SMOIS

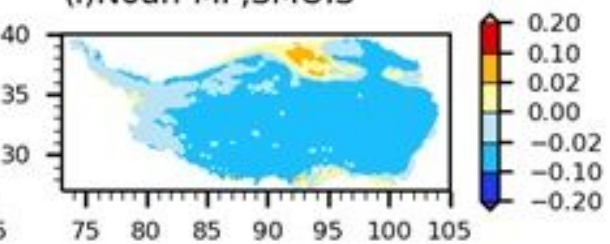

Figure 13

Similar to Fig. 12 , but in the $-5^{\circ} \mathrm{C}$ experiment.

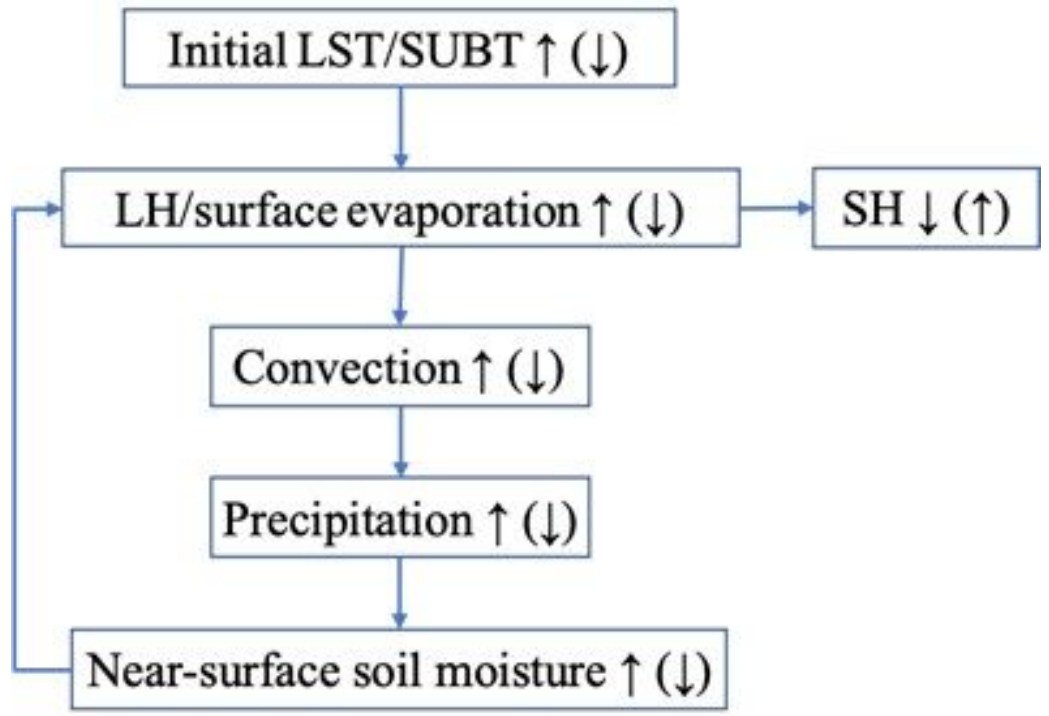

Figure 14

Feedbacks caused by the imposed LST/SUBT initial anomalies between the surface heat fluxes (sensitive/latent heat fluxes, SH/LH), surface evaporation, convection in the atmosphere, precipitation, 
and soil moisture at the near-surface layers in CLM and Noah-MP, in which $\uparrow(\downarrow)$ means increase (decrease).

\section{Supplementary Files}

This is a list of supplementary files associated with this preprint. Click to download.

- LS4PsupplementaryR1.docx 